\title{
Market Penetration of New Energy
} Technologies

\author{
Daniel J. Packey
}

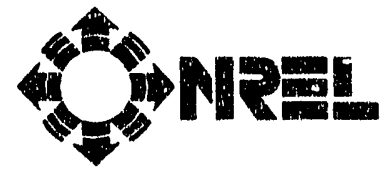

National Renewable Energy Laboratory

(formerly the Solar Energy Research Institute) 1617 Cole Boulevard Golden, Colorado 80401-3393

A Division of Midwest Research Institute Operated for the U.S. Department of Energy under Contract No. DE-AC02-83CH10093

Prepared under Task No. AS815440

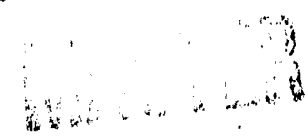

February 1993 


\section{NOTICE}

This report was prepared as an account of work sponsored by an agency of the United States government. Neither the United States government nor any agency thereof, nor any of their employees, makes any warranty, express or implied, or assumes any legal liability or responsibility for the accuracy, com. pleteness, or usefulness of any information, apparatus, product, or process disclosed, or represents that its use would not intringe privately owned rights. Reference herein to any specific commercial product, process, or service by trade name, trademark, manufacturer, or otherwise does not necessarily constitute or imply its endorsement, resommendation, or favoring by the United States government or any agency thereof. The views and opinions of authors expressed herein do not necessarily state or reflect those of the United States government or any agency thereof.

\section{Printed in the United States of America Available from: \\ National Technical Information Service \\ U.S. Department of Commerce \\ 5285 Port Royal Road \\ Springfield, VA 22161}

Price: Microliche A01

Printed Copy A04

Codes are used for pricing all publications. The code is determined by the number of pages in the publication. Information pertaining to the pricing codes can be found in the current issue of the following publications which are opnerally available in most libraries: Energy Research Abstracts (ERA); Governmeilt Reports Announcements and Index (GRA and I); Scientific and Technical Abstract Repoits (STAR); and publication NTIS-PR-360 available from NTIS at the above address. 


\section{Preface}

The Analytic Studies Division of the National Renewable Energy Laboratory prepared Market Penetration of New Energy Technologies for the Office of Utility Technologies, Assistant Secretary for Conservation and Renewable Energy, U.S. Department of Energy.

My special thanks goes out to Mary Anne Dunlap and the Word Processing Department at the National Renewable Energy Laboratory for their hard work and patience. In addition, I would like to thank the reviewers, Lynn Coles and Ron White (at NREL) and John Mitchiner (at Sandia National Laboratory), for their insightful comments. Finally, I would like to thank Tom Holt for his work on the graphs presented in this report. 


\section{Executive Summary}

Market Penetrativin of New Energy Technologies examines the characteristics, advantages, disadvantages, and, for some, the mathematical formulas of several forecasting methods. Some of the methods examined have already been used for renewable energy technologies (RETs); others have been used for other new technologies but can be effective methods for RETs as well.

When choosing the most appropriate forecasting method, analysts should consider how the different market penetration potentials of different technologies relate to each other. All technologies have different potentials of market penetration-theoretical, technical, economic, and the projected market (Figure S-1). Market penetration analysis focuses on projected market, or market share.

This study reviews seven forecasting methods that include 30 techniques. These methods range from simple judgmental forecasting to complex simultaneous equation systems. Among the methods studied are subjective estimation, market surveys, historical analogy models, cost models, diffusion models, time-series models, and econometric models.

This wide variety of forecasting methods gives analysts several options from which to choose the best fit for their needs and resources. In some instances, the best prediction tool is a combination of methods. For this reason, the study describes a variety of costing methodologies that are effective when linked with some forecasting techniques.

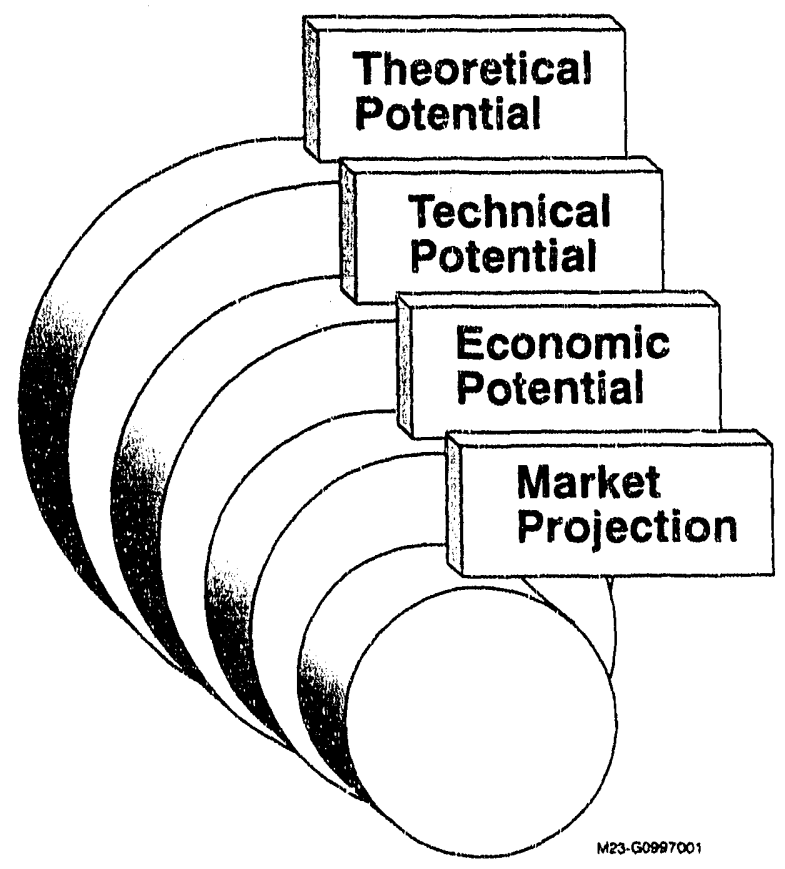

Figure 5-1. Every new technology has different potentials of market penetration. Market penetration analysis focuses on the last and smallest section, market projection. 
A wide selection of techniques is essential for analysts challenged with forecasting the market penetration of new technologies. These technologies are in various stages of development and have varying amounts of data available about them. For example, some RETs are so new or are evolving so rapidly that much data about them are lacking. In these cases, techniques demanding less data and resources should be used. Other RETs have a longer track record so more quality data are available. To obtain the most statistically significant prediction, the most sophisticated method that fits the data available should be used.

Some prediction methods are more effective than others at different developmental stages of new technologies (Figure S-2). Generally, as the new technology matures, the amount of data about that technology increases, allowing use of more sophisticated data-demanding methods that require more resources for analysis.

Market Penetration of New Energy Technologies contains an extensive, up-to-date bibliography in which analysts can locate material that details various forecasting techniques. The bibliography also includes some citations on special topics related to market forecasting such as small-sample properties of econometric techniques.

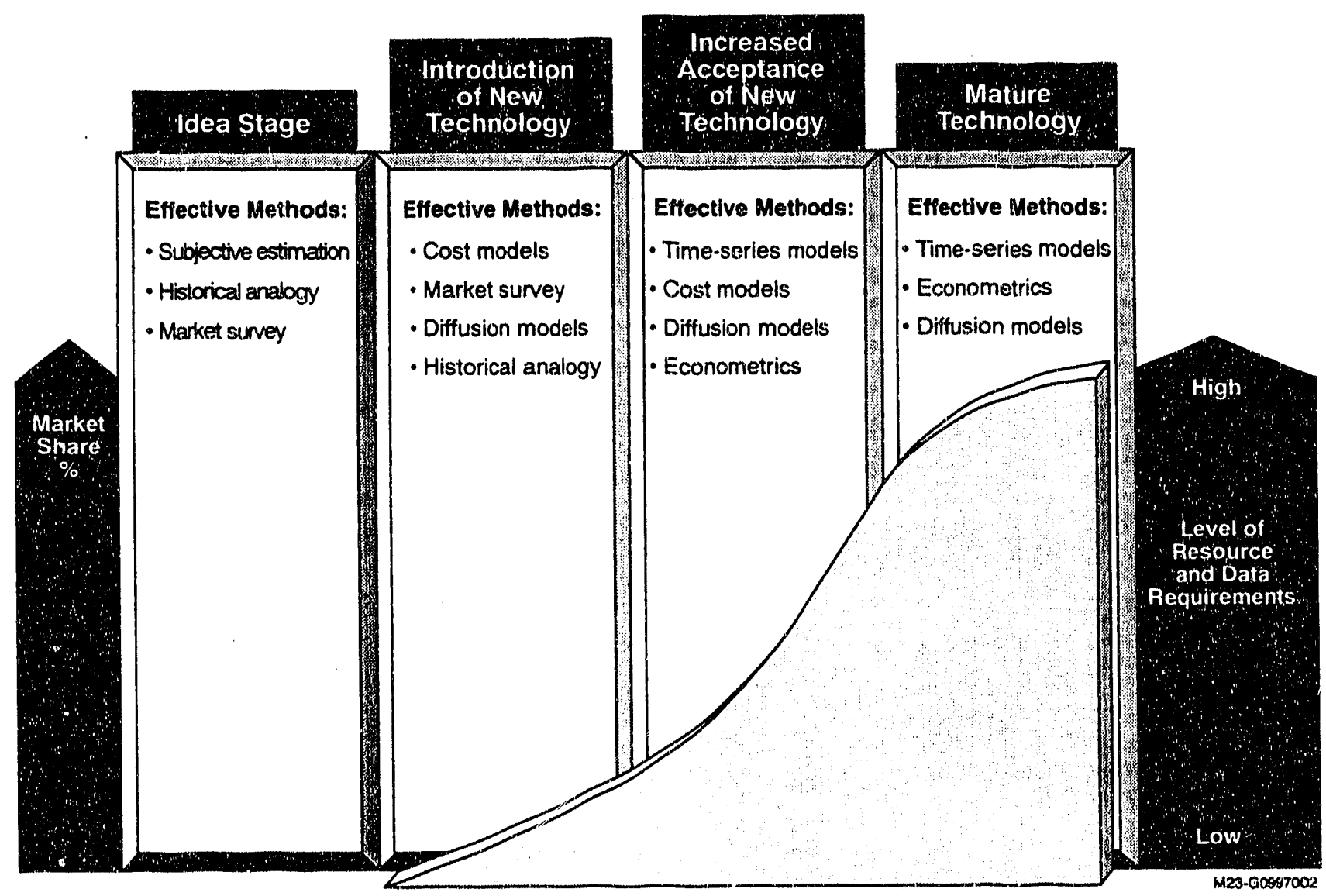

Figure S-2. Some prediction methods are more effective that other's at different developmental stages of new technulogies. 


\section{Table of Contents}

$\underline{\text { Page }}$

Introduction and Statement of Purpose $\ldots \ldots \ldots \ldots \ldots \ldots \ldots \ldots \ldots \ldots \ldots \ldots$

Section 1: Subjective Estimation Methods $\ldots \ldots \ldots \ldots \ldots \ldots \ldots \ldots \ldots \ldots$

Panel Consensus Method $\ldots \ldots \ldots \ldots \ldots \ldots \ldots \ldots \ldots \ldots \ldots \ldots \ldots \ldots$

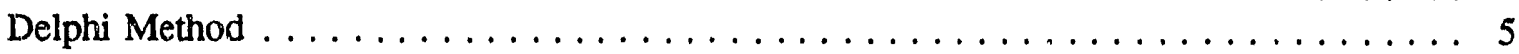

Section 2: Market Surveys $\ldots \ldots \ldots \ldots \ldots \ldots \ldots \ldots \ldots \ldots \ldots \ldots \ldots \ldots$

Evaluation $\ldots \ldots \ldots \ldots \ldots \ldots \ldots \ldots \ldots \ldots \ldots \ldots \ldots \ldots \ldots \ldots \ldots$

Section 3: Historical Analogy Models $\ldots \ldots \ldots \ldots \ldots \ldots \ldots \ldots \ldots \ldots \ldots \ldots \ldots$

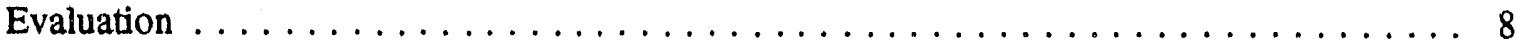

Section 4: Cost Models $\ldots \ldots \ldots \ldots \ldots \ldots \ldots \ldots \ldots \ldots \ldots \ldots \ldots \ldots \ldots$

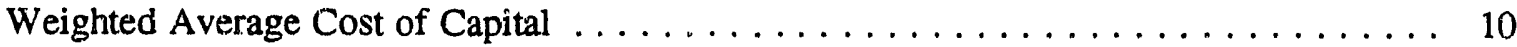

Marginal Cost of Capital . . . . . . . . . . . . . . . . . . . . . . . . 10

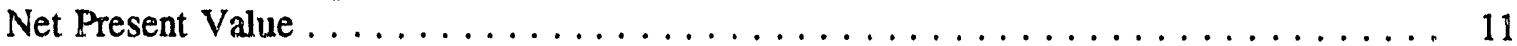

Total Life-Cycle Cost . . . . . . . . . . . . . . . . . . . . . . . . . . . . . . 12

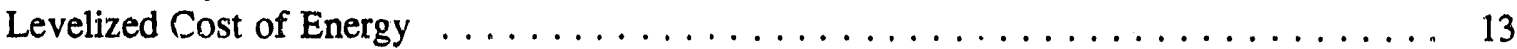

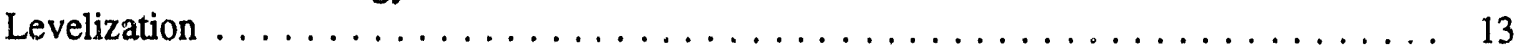

Revenue Requirements $\ldots \ldots \ldots \ldots \ldots \ldots \ldots \ldots \ldots \ldots \ldots \ldots \ldots \ldots$

Internal Rate of Return $\ldots \ldots \ldots \ldots \ldots \ldots \ldots \ldots \ldots \ldots \ldots \ldots \ldots \ldots$

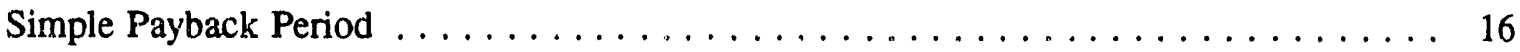

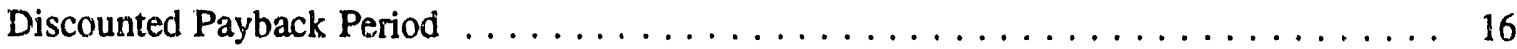

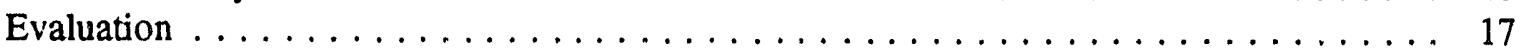

Section 5: Diffusion Modeis $\ldots \ldots \ldots \ldots \ldots \ldots \ldots \ldots \ldots \ldots \ldots \ldots \ldots$

Bass Model $\ldots \ldots \ldots \ldots \ldots \ldots \ldots \ldots \ldots \ldots \ldots \ldots \ldots \ldots \ldots \ldots \ldots \ldots$

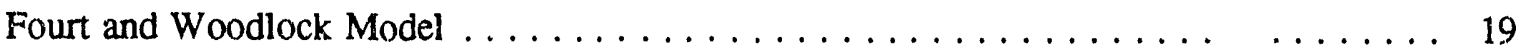

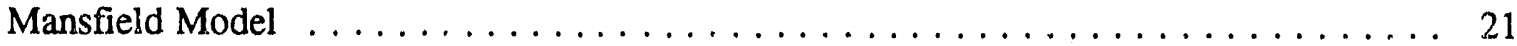

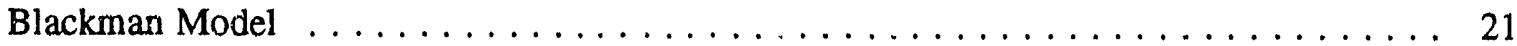

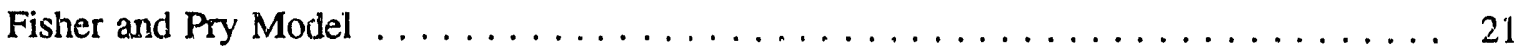

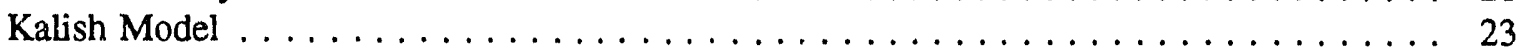

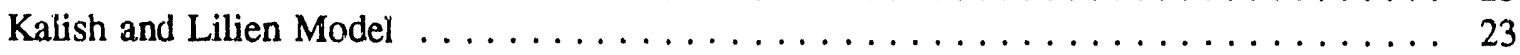

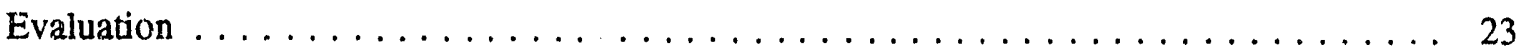

Section 6: Time-Series Models . . . . . . . . . . . . . . . . . . . . 27

Simple Deterministic Extrapolation Models $\ldots \ldots \ldots \ldots \ldots \ldots \ldots \ldots \ldots \ldots \ldots$

Stochastic Time-Series Models . . . . . . . . . . . . . . . . . . . . . . . 29

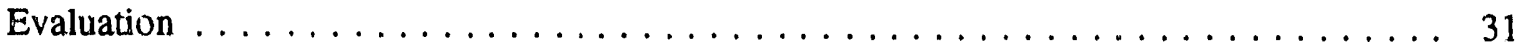




\section{Table of Contents (concluded)}

Page

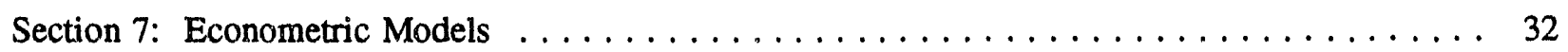

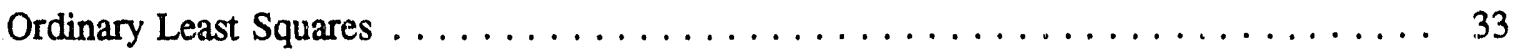

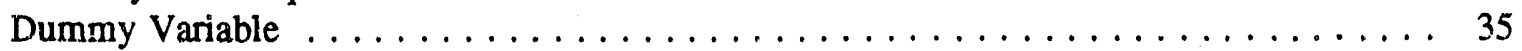

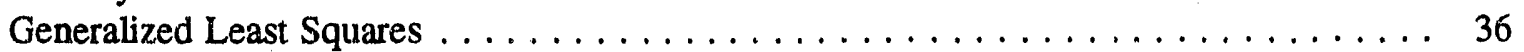

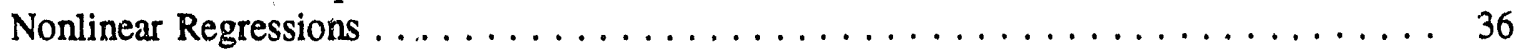

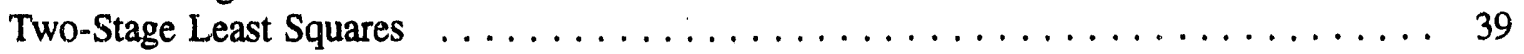

Seemingly Unrelated Regression $\ldots \ldots \ldots \ldots \ldots \ldots \ldots \ldots \ldots \ldots \ldots \ldots \ldots \ldots \ldots$

Evaluation $\ldots \ldots \ldots \ldots \ldots \ldots \ldots \ldots \ldots \ldots \ldots \ldots \ldots \ldots \ldots \ldots \ldots \ldots$

Section $8:$ Summary and Conclusions $\ldots \ldots \ldots \ldots \ldots \ldots \ldots \ldots \ldots \ldots$

References $\ldots \ldots \ldots \ldots \ldots \ldots \ldots \ldots \ldots \ldots \ldots \ldots \ldots \ldots \ldots \ldots \ldots \ldots \ldots \ldots$

Bibliography $\ldots \ldots \ldots \ldots \ldots \ldots \ldots \ldots \ldots \ldots \ldots \ldots \ldots \ldots \ldots \ldots \ldots$ 


\section{List of Tables}

Page

Table $5-1$. Alternative Specifications for $F(t) \ldots \ldots \ldots \ldots \ldots \ldots \ldots$

\section{List of Figures}

Figure 4-1. Comparison of nominal and present values of the

Page

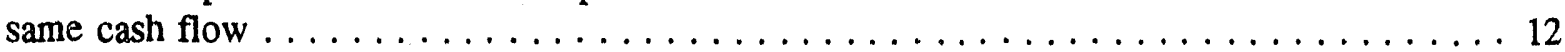

Figure 4-2. Comparison of cash flow with a levelized cash flow $\ldots \ldots \ldots \ldots \ldots \ldots$

Figure 5-1. The Bass new product diffusion model: (a) adoptions due to external and internal influences in the Bass model; (b) analytical structure of the Bass model

Figure $7-1$. Ordinary least squares regression $\ldots \ldots \ldots \ldots \ldots \ldots \ldots \ldots$

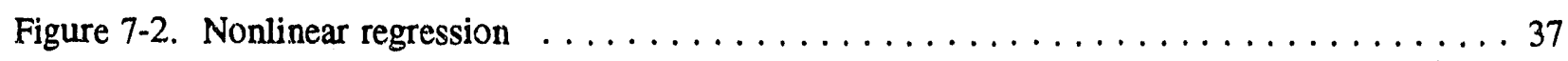

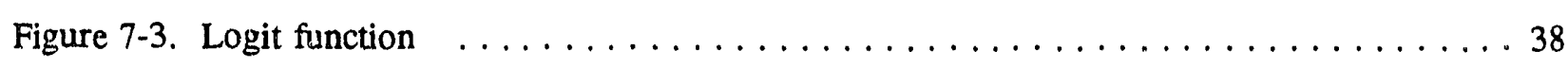




\section{Introduction and Statement of Purpose}

Market penetration of renewable energy technologies (RETs) is dependent on both achieving market viability and the dynamics of the market penetration process itself. This report examines the effects and implications of different market penetration forecasting methodologies. It reviews the literature on market penetration and its use and verification in practice. Emphasis is given to previous work done on energy technologies and the application of market penetration formulations in energy/economic models. However, attention is also given to those studies wherein important advances in thought or purpose are made, regardless of the subject market. Considerations of special importance to market penetration modeling are identified and discussed. Where practicable, information obtained from Key Stakeholders Analysis, Phase I (NREL/TP-261-4704) (Draft) is cross referenced.

The surpose of this report is to present the reader with a wide variety of market penetration modelling techniques. It is not possible to anticipate every situation. This report is designed to provide the analyst with the options available given certain conditions. No one approach is correct for every circumstance. The general recommendation is to use the most sophisticated technique supported by the available data.

This report examines the methods used to predict the market penetration of new technologies. In reviewing the literature, we found (as did EPRI 1982) that the term "market penetration," is not clearly defined in the literature. For certain groups, market penetration analysis focuses only on diffusion methods. For other groups, market penetration analysis encompasses time-series and econometric models. In some instances, the term "technical substitution models," was used to indicate routine market substitution activities. In other instances, the term "technical substitution model," reflected a model that analyzed the introduction of advanced new technologies. We focused on the market penetration of new technologies that could be applicable to RETs and not on minor changes in existing technologies. Moreover, we made an effort to respect author-defined model types. For example, all diffusion models are presented in the section on diffusion models. When overlapping situations occur, the reader is directed to another section for elaboration of a point not felt to be germane to the section.

This report will:

- Review the literature on market penetration, with particular attention placed on those market penetration techniques that may be applicable to RETs.

- Discuss and illustrate the techniques used in market penetration analysis.

Identify pertinent information valuable in the assessment of the market penetration models.

- Profile some of the important factors (e.g., the ability to incorporate uncertainty analysis) in the consideration of the different market penetration methods.

- Summarize and evaluate the market penetration methods.

Ir : order to achieve these goals, this study examined the characteristics, advantages, disadvantages, and, at times, the actual mathematical formula of the model.

Given the nature of RETs, we adopied a pragmatic approach for this report on market penetration models. The data available for the analysis of RETs are not homogeneous. In some circumstances, there exists a rich data base and, in other areas, the data are limited or even lacking. Moreover, RETs have a tendency 
Given the nature of RETs, we adopted a pragmatic approach for this report on market penetration models. The data available for the analysis of RETs are not homogeneous. In some circumstances, there exists a rich data base and, in other areas, the data are limited or even lacking. Moreover, RETs have a tendency to be regionally specific. Consequently, cases develop in which even data on the same RET may not be generalized for a different region (e.g., regional climatic differences).

This situation necessitated a broad review of the available market penetration models. Circumstances dictated (primarily data limitations) that the more elaborate models were not feasible. Consequently, the more esoteric models, such as spectral analysis, are not included. Moreover, composite system dynamics approaches (e.g., Fossil2, C.O.A.L. and Vescuso's model) were not reviewed. Specifically, Fossil2 was not reviewed because (1) Fossil2 is much more than a market penetration model, and (2) as a composite system dynamics model, Fossil 2 utilizes a variety of approaches. For example, cost models and a logistic curve are incorporated in Fossil2. As such, there is not a unique approach to describe but rather, a combination of approaches.

Composite models themselves are not uniform; different composite models choose different items on the market penetration methodology menu. Therefore, even though we do not address composite models per se, we do address the individual models that make up the composite models. The logic behind this approach is that once you understand the methods that make up the model, you are in a better position to evaluate the model itself.

We strove to be consistent. Not only do we address composite models from their individual market penetration segments but we address other models in the same fashion. For example, cost models are often combined with other model forms, such as diffusion models, to model market penetration. A common approach used to estimate the market penetration of solar technologies (and other RETs) is to use a logistic curve incorporating cost data (Warren 1980).

Models and methods are used for a variety of purposes. Tactically speaking, it was necessary to choose a section to present each method. For example, the logistic curve is addressed in the diffusion model section of this report. Therefore, in order to avoid repetition, only the specified model components are discussed in each section. The other model structures are discussed in their appropriate sections, and mention is made when other models or methods can be incorporated.

To provide meaningful support for technologies that are newly emerging, it was necessary to present the simpler, less data-demanding techniques. However, we made efforts to illustrate some of the more advanced techniques when practicable. Thus, advanced techniques, which in some instances could be useful, are presented. For example, we introduce a heretofore unused approach for market penetration analysis, Zellner's seemingly unrelated regression. This new method is an econometric approach that allows for the simultaneous examination of interactive influences across a number of RETs.

We considered the following market penetration methods:

- Subjective estimation methods

- Market surveys

- Historical analogy models

- Cost models

- Diffusion models 
- Time-series models

- Econometric models. 


\section{Section 1: Subjective Estimation Methods}

When dealing with forecasting methodologies, one has to be careful not to fall into the trap of characterizing one technique as subjective (e.g., judgmental forecasting) and another technique as nonsubjective (e.g., econometric). Even the most technically objective forecasting models require many subjective assumptions (Tyebjee 1987). The choice of a particular data transformation or of a particular functional form, seemingly only a technical detail, can and does change a model's forecast (Wachs 1982). Thus, the choice of a proper modeling technique cannot be one of a subjective (normative) versus objective (positive) model in a Friedmanian sense (Friedman 1953). But rather, the choice of an appropriate modeling technique resides along a subjective input continuum, with judgmental forecasting methods at one extreme and randomly selected samples, employing statistically valid and theoretically correct econometric analysis, at the other.

No matter how sophisticated the analysis, there will always remin a certain amount of residual uncertainty. This residual uncertainty necessitates a degree of subjective judgment to be used by the analyst in the forecast modeling process (Raju and Teotia 1985). Because of the newness of the innovation process itself, residual uncertainties and poor market data are the normal condition when analyzing the market penetration of new or emerging technologies. Thus, adjustments and decisions on the sufficiency of modeling techniques must be made accordingly.

Subjective estimation methods or judgmental forecasting methods can be simple: a sole entrepreneur's decision to market a product based on intuition or gut-feelings. Or these methods can be complex: a formal decision-making process utilizing a panel consensus or Delphi ruethod (Geurts and Reinmuth 1980). The market penetration method may be a simple brainstorming sessioat or complexly morphological. It may or may not require detailed quantitative or qualitative data as input. The critical identifying distinction, separating it from all other methods, is that for subjective estimation methods the evaluation and transformation of the information from raw data to a market penetration forecast is carried out primarily within the human brain (EPRI 1991).

Although an Electric Power Research Institute (EPRI) study found that utilities tended to use the more sophisticated methods, a majority of manufacturing companies relied on expert judgment and time-series models to forecast new product sales (EPRI 1991). Thus, we have focused a significant portion of our attention on those areas. Subjective estimation methods are typically used when there is little or no historical data or when existing data is suspect (EPRI 1991). Two subjective estimation techniques will be discussed: the panel consensus method and the Delphi method.

\section{Panel Consensus Method}

In the panel consensus method, key centralized decision makers, or a group of top management personnel, experts, and other individuals who are knowledgeable about the new technology, are brought together to determine subjective estimates of a product's market penetration. This technique assumes that the organization possesses (or has access to) experts who have special knowledge of the new technology and use this knowledge to effectively forecast the product's market development. It assumes that each expert recognizes the other sxperts' importance and accepts their input in a consensus-building activity. Each recognizes the special competence of the others and thus the group benefits through the assimilation of the experts' collective knowledge (Geurts and Reinmuth 1980). Experts may internally make the decision (e.g., a company employing in-house experts) or just provide information to key centralized decision makers (e.g., an executiv€ board or regulatory body). 
One example of successfully using the panel corsensus method is the creation of the report: The Potential of Renewable Energy: An Interlaboratory White Paper. Experts from Idaho National Engineering Laboratory, Los Alamos National Laboratory, Oak Ridge National Laboratory, Sandia National Laboratory, and the National Renewable Energy Laboratory (NREL) cooperated with more than 30 experts from universities, industry, and policy analysis organizations in order to develop the information presented in the report. ${ }^{1}$

\section{Evaluation}

Two main areas of difficulty exist in the panel consensus method. The first problem area concerns pe:sonalities. Personality or enthusiasm, rather than positions of logical merit, may play an overly important role in the consensus agreement (Raju and Teotia 1985). A dominant or overiy optimistic personality could attempt to override the other panel members by force of character (Tyebjec 1987). Tyebjee identifies this as advocate or optimist bias. In addition, other personality-based problems may exist. Experts, in general, have invested significant amounts of personal capital in their achievement of "expert" status. Consequently, it is not unheard of that an expert should desire that his/her position be adopted. For expert consultants, there is also a monetary incentive to have the consultant's position adopted and, as a consequence, have the consultant's reputation enhanced. Moreover, it is not a foregone conclusion that any one group of experts will agree on any one topic. Consequently, professional disputes may arise, and these disputes may make the arrival of a consensus position extremely difficult or impossible. Finally, personality clashes may also arise, which interfere with consensus. building (Geurts and Reinmuth 1980).

The second problem area concerns the hierarchical status of the individuals who make up the panel. Hierarchial bias may become a factor. Lower ranking experts may be hesitant to criticize or argue rith a higher ranking individual. Thus, the r rguments of a higher ranking individual may be given greater weight than if the sarne position were held by someone of lesser rank. This is acceptable if the highranking individual is an expert in the field. However, hierarchical bias may be a significant problem when the technology is sufficiently new to upper management to be relatively unknown and the specialized expertise on the new technology resides in the mid-level line and staff employees (Geurts and Reinmuth 1980).

\section{Delphi Method}

The Delphi approach uses an iterative process to obtain the consensus opinion of a group of experts (EPRI 1991). An anonymous panel of experts is selected, and their individual subjective estimates are recorded. There are no group meetings. Consequently, the subjective estimates are unaffected by personalities or group dynamics. First-round results are pooled and distributed among the anonymous panel of experts, and the experts are asked to make revised estimates and to justify their estimates. The process continues until a consensus is reached or the forecasters no longer change their estimates (Geurts and Reinmuth 1980). Thus, the Delphi approach features anonymity and an iterative feedback loop among the expert participants (EPRI 1991).

\footnotetext{
'The panel conseasus method used for the white paper was modified. First, experts would form technology groups. Second, the technology groups would arrive at technology penetration estimates based on an estimated levelized cost method in a market setting. Finally, the technology groups would defend the technology estimates in front of a broader group consisting of all the researchers.
} 


\section{Evaluation}

The main drawbacks to this subjective estimation method are that the approach is individual dependent, and judgmental approaches do not produce statistically valid results. As the level of subjective input increases, so does the relative importance of the forecaster's opinion. All subjective input are not created equal. The value of the subjective estimates of a 30-years-in-the-business professional may not be on a par with someone new to the market. The experienced professional may informally or implicitly take into consideration factors that are not easily (or caunot be) modeled. Business climate, timing, customer attitudes, or the relative degree of market softness are examples of important but difficult-to-measure factors.

An additional drawbark to the judgmental approach is that the expertise required for the execution of this method is not easily uransferred from one individual to another. Personal experience, by its nature, is in lividual. Gut-level (or market-savvy) feelings may take years (if it is possible at all) to explain to or to install in subsequent decision makers. Finally, the predictive powers of subjective estimation methods are generally not subjected to rigorous analysis (EFRI i991). This is indicated by the success and failure attributions. There appears to exist a tendency to attribute success to one's skill and failure to chance, with past failures discounted (Tyebjee 1987). 


\section{Section 2: Market Surveys}

The purpose of market surveys is to obtain information from decision makers on their decision-making criteria, technological preferences, and planned behavior. In addition, market surveys can be used to elicit responses from decision makers on their willingness to consider new technologies and on those factors the decision makers view as decisive. In certain circumstances, market surveys can aid in decision modelirg. One example is the application of decision modeling to the acceptance of new electricitygenerating technologies (Stover 1978).

Market surveys for new products or technologies are sometimes rererred to as intention surveys. Intention surveys are commonly used for automobiles and can be used for new technologies as well (Raju and Teotia 1985). Market or intention surveys for new technologies càn be accurate if the following conditions are met (EPRI 1991):

- Event falls within a forecast horizon of two years or less

- Forecasted event is important to the people surveyed

- Respondents have definite behavioral plans

- Respondents can be relied upon to report correctly

- Respondents have the authority and ability to actuate planned behavior

New information is unlikely to radically change the respondents' plans.

\section{Evaluation}

There are sevrral potential problem areas for market or intentions surveys. First, intentions and actual behavior are not identical. Expected future behaviors are subject to change and can change as a result of market forces not anticipated by the survey or included in the survey's design. Second, the individuals answering the survey may not be in a sufficient authority position to actuate the planned behavior. Third, the individual may not be sufficiently knowledgeable of the new technology to assess the marketability of the new technology or its potential impact on the market. Fourth, the predictive power of the survey's planned behavioral responses is valid for 1 limited period of time (Raju and Teotia 1985). Fifth, businesses tend to be secretive about their planned intentions (EPRI 1991). Finally, even if businesses do respond, it may be difficult to obtain a full and truthful revelation of their preferences (Varian 1984). 


\section{Section 3: Historical Analogy Models}

Historical analogy is a prediction method that compares an existing product's market pattern to a new product or technology. The market penetration path is assumed to be the same for both technologies. Historical analogy models generally assume that the technologies are of a sufficiently analogous nature as to exist in approximately identical market structures. If this is the case, then the new technology's market penetration share will approximate the existing technology's market penetration share's pattern over the technology's life cycle. The historical analogy model can be particularly useful for introducing new technology in different regions. In this case, the life-cycle adoption rates for a new technology in one region may provide a suitable approximation for the market penetration rates of the new technology in another region (EPRI 1982). ${ }^{2}$ However, the historical analogy model does rot explicitly consider other non-time exogenous variables (Raju and Teotia 1985).

\section{Evaluation}

There are two main areas of concern. First, the analysis hinges on the appropriateness of the analogous technology. For tightly aligned technologies, historical analogy may be sufficient. However, the existence of a closely aligned technology may be a mixed blessing. A closely aligned technology may represent additional potential competition; competition that did not exist when the closely aligned product or technology was introduced. For loosely related technologies, the accuracy of historical analogy methods may rapidly deteriorate. Such may be the case for truly novel or pioneering technologies (EPRI 1991).

Second, the historical analogy model does not take into consideration non-time exogenous variables. Consequently, the explanatory value of this type of model is limited. Moreover, in situations where there is sufficient historical data, alternative, more sophisticated modeling techniques, ${ }^{3}$ such as time-series or econometric methods, may provide rnore meaningful estimates.

2This point is discussed in the comments on the "neighborhood effects," in the diffusion model section of this report.

${ }^{3}$ Some of these estimating techniques will be discussed in subsequent portions of this report. 


\section{Section 4: Cost Models}

Cost models estimate market penetration as a function of the cost-related aspects of the product or technology. Cost estimates and the discount rate are typically used as the critical factors. A range of technologies are selected, and the cost estimates are calculated. These cost estimates are then normalized. The comparative normalized cost of the technology is then used to calculate the product or technology's annual and long-run market share (EPRI 1982). Thus, cost models, on their own merit, are used to determine the adoption of new technologies.

However, cost models are often combined with other model forms, such as diffusion models, to model market penetration. A common approach used to estimate the market penetration of solar technologies (and other RETs) is to use a sigmoid-shaped logistic curve incorporating cost data (Warren 1980). The logistic curve is addressed in the diffusion model section of this report. Therefore, in order to avoid repetition, only the cost model components will be discussed in this section. The other model structures will be discussed in their appropriate sections, and mention will be made when cost models can be incorporated.

There are generally four phases incorporated in cost models. First, the set of competing technologies are identified. Second, the initial and after-tax costs are estimated over the life of the technology. Third, a cost model is selected, and the costs are organized so that they can be caiculated in a comparable fashion. Finally, the degree of market penetration of each technology is estimated from the normalized cost (Raju and Teotia 1985; and Weijo and Brown 1988).

Because there are many cost models (Raju and Teotia 1985) it was necessary to select a manageable subset of the available models. We selected the following 10 commonly used methods to discuss in this report:

Weighted average cost of capital

- Marginal weighted average cost of capital

- Net present value

- Total life-cycle cost

I.evelized cost of energy

- Levelization

${ }^{4}$ For example, the market share equation could be specified as

$$
\mathrm{Ms}_{\mathrm{i}}=\frac{\mathrm{C}_{\mathrm{i}}^{\gamma}}{\sum_{i=1}^{0} \mathrm{C}_{\mathrm{i}}^{\gamma}}
$$

where $M s_{i}$ is the market share and $C_{i}$ represents the cost of technology $i$. 
- Revenue requirements

- Internal rate of return

- Simple payback period

- Discounted payback period.

Most of these models focus on obtaining an accurate estimate of capital costs. This is intentional on our part. There are two reasons for this. First, RETs are typically characterized as having significant capital costs and low energy costs. Second, most utilities (a significant purchaser of RETs) have some form of passing through energy costs to their custorners, whereas additional capital costs are ofteri scrutinized within a regulatory environment. Consequently, utilities examine capital costs closely and make decisions based upon the output of capital costing methods. These models can be constructed on spreadsheet software (e.g., Lotus 123 or Excel), although some may result in large extended files. EPRI includes software in its 1991 Technical Assistance Guide (TAG), which includes the more difficult models (such as revenue requirements).

\section{Weighted Average Cost of Capital}

The implicit assumption made when using the weighted average cost of capital (WACC) is that the past rates available to the firm, for the acquisition of debt and equity, will be available to the firm in the future. The general WACC formulation is calculated by

$$
W A C C=r_{E}\left[\frac{E}{(D+E)}\right]+r_{D}\left[\frac{D}{(D+E)}\right]
$$

where WACC is the weighted average cost of capital, $r_{E}$ is the rate of return on equity, $r_{D}$ is the after-tax debt rate, $D$ is the market value of debt and $E$ is the market value of equity (Au and $A u$ 1983).

Decomposing the equity term into its component parts and separating out the tax rate, the aggregated weighted average cost of capital can be estimated from the following:

$$
W A C C=r_{\infty}\left[\frac{C_{o}}{\left(C_{e}+P_{t}+D\right)}\right]+r_{e p}\left[\frac{P_{s}}{\left(C_{e}+P_{e}+D\right)}\right]+(1-T) r_{d}\left[\frac{D}{\left(C_{e}+P_{e}+D\right)}\right]
$$

where $r_{e c}$ is the rate of return on common equity, $C_{e}$ is equal to new issue common stock and corporate retained earnings (Weston and Brigham 1981), $P_{\text {, }}$ is equal to the new issue preferred stock, $D$ equals the new debt issues, $r_{e p}$ is the rate of return on preferred stock, $T$ equals the corporate tax rate, and $r_{d}$ is the rate on debt. It is important to match as closely as possible the cost of capital to the nation, region, industry, or even company, depending on the level of detail necessary for the analysis. The return rate on debt and equity will depend on relative financial strength.

\section{Marginal Cost of Capital}

If the past rates available to the firm for the acquisition of its needed debt and equity are not available to the firm in the future, then WACC may not be appropriate to use. The new cost of debt and equity (i.e., the marginal cost of capital [MCC]) could be more appropriate.

There are four steps in the calculation of the MCC. First, calculate the present total cost of capital. Second, identify the total cost of capital after the change has occurred. Third, subtract the pre-change 
total cost of capital from the post-change total cost of capital. Fourth, divide the total cost of capital difference by the amount of the new debt. Thus, the general MCC can be expressed as:

$$
\mathrm{MCC}=\frac{\text { NATCC }- \text { OATCC }}{\text { ANF }}
$$

where MCC is the marginal cost of capital, NATCC is the new annual total cost of capital, OATCC is the old annual total cost of capital, and ANF is the amount of new financing (Brown and Yanuck 1980).

A situation may develop in which the new technology is produced by one or two firms. In this case, a conservation and renewable energy analyst may be called upon to estimate the cost of capital for an individual company. For example, information may be needed about the cost of capital for a prototypical company that produces a renewable energy technology. For a specific company, the cost of new common stock issues is calculated as follows:

$$
C C S=\left[\frac{\text { DIVID }}{(1-\text { Float })}\right]+g
$$

where CCS is the cost of new common stock issues, DIVID is the dividend yield, Float is a broker's percentage fee for selling the stock, and $\mathrm{g}$ is the yield growth rate (Weston and Brigham 1981).

\section{Net Present Value}

Net present value is typically the textbook standard for business decision making and used so extensively, for such a wide variety of purposes, that no discussion of costing methods would be complete without it. The net present value (NPV) is the time valued revenue stream less the costs generated from a project (Palm and Qayum 1985). Assuming constant ${ }^{6}$ dollars and a real discount rate, the NPV can be expressed as the discounted difference between the cost and revenue streams of a project $n$

$$
N P V_{0}=\left(R_{0}-C_{0}\right)+\frac{\left(R_{1}-C_{1}\right)}{(1+d)}+\frac{\left(R_{2}-C_{2}\right)}{(1+d)^{2}}+\cdots+\frac{\left(R_{a}-C_{2}\right)}{(1+d)^{n}}+\frac{S}{(1+d)^{2}}
$$

where $\mathrm{NPV}_{0}$ is the net present value of the projected project, $R_{4}$ is the revenue (given in constant dollars) received at time $t, C_{t}$ is the cost (also given in constant dollars) incurred at time $t, d$ is the real discount rate, $\mathrm{n}$ is the number of years in the time period considered, and $S$ is the expected salvage value of the asset discounted to the year $\mathrm{n}$. The effect of taking the present value of a cash flow is illustrated in Figure 4-1.

\footnotetext{
sTo the best of the author's knowledge, there exists no estimate of a national flotation rate. Flotation rates are determined strictly on a company-by-company basis.

The analysis could also be conducted using current dollars. What is important, however, is that whichever type of dollars is being used, it is used consistently. For example, the analyst always compares constant dollars to constant dollars or current dollars to current dollars.
} 


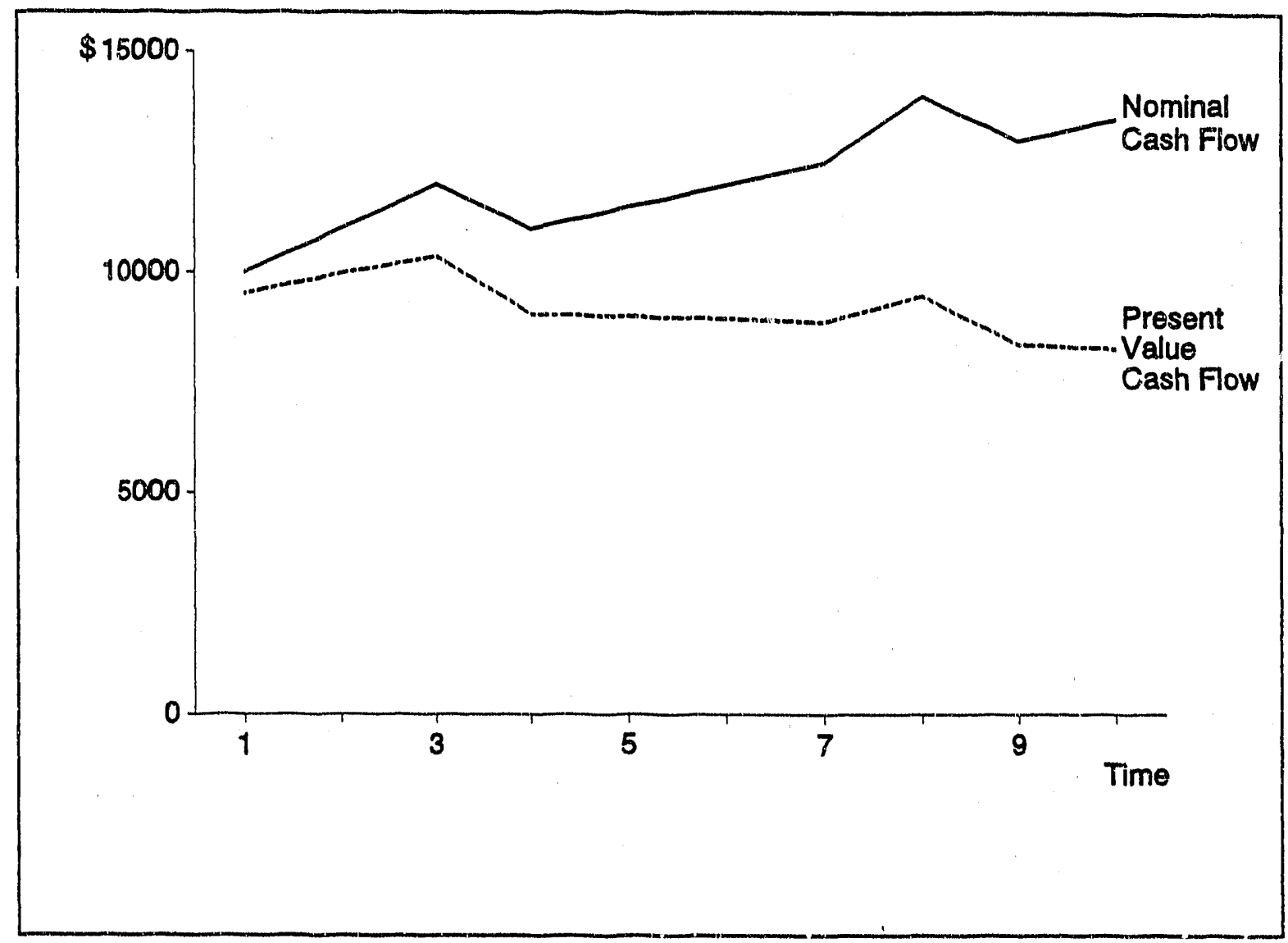

Figure 4-1. Comparison of nominal and present values of the same cash flow

\section{Total Life-Cycle Cost}

Total life-cycle costs (TLCC) are the total costs incurred through the ownership of an asset over the asset's life span (Brown and Yanuck 1980). The TLCC type of analysis takes into consideration all significant dollar costs (in time equivalent form) that are incurred as a result of the project. Positive discounted values of revenues are treated as negative costs and are subtracted from total costs on an equivalent time basis (i.e., discounted). TLCC can then be represented as

$$
\text { TLCC }=I-S+M+R+E
$$

where TLCC is the present value of the total life-cycle cost, $I$ is the present value of the investment costs (including finance charges), $S$ is the present value of the expected salvage value, $M$ is the present value of the non-fuel operation and maintenance and repair costs, $R$ is the present value of the replacement costs, and $E$ is the present value of the energy costs (Ruegg 1987).

Total life-cycle cost is composed of the present value of many different types of costs. Care should be taken that equivalent present value techniques are used on all of the components of TLCC. The estimated dollar value for operations and maintenance expenses are often not of the same form as the estimated dollar values for the other costs. For example, if operations and maintenance expenses are calculated by multiplying the level of output by some fixed proportion, then the result of this method of calculating the 
operations and maintenance expenses is not a present value for operations and maintenance expenses. This would introduce bias into the estimate of TLCC.

\section{Levelized Cost of Energy}

The levelized cost of energy is used to compare alternative energy generating or producing technologies. Generally, comparisons between the cost of energy generated by a renewable energy resource and a standard generation unit consuming fossil fuel could use the levelized cost of energy in its analysis. More specifically, the levelized cost of energy approach is used by the U.S. Department of Energy for use in many of its five year research and development plans and NREL's Renewable Energy Technology Evolution Rationales.

The levelized cost of energy (LCOE) is the dollar amount that must be recovered for each unit of energy produced over the lifetime of the system, which, if discounted according to when it is produced, will equal the discounted life-cycle cost of the system. LCOE is represented as

$$
L C O E=\frac{T L C C}{\sum_{r=1}^{W}\left[Q_{t} \div(1+d)\right]}
$$

where LCOE is the levelized cost of energy, TLCC is the total life-cycle cost, $Q_{t}$ is the firm's energy output at time $t, d$ is the discount rate, and $\mathrm{N}$ is the number of tims periods (Short 1983). It is interesting to note that if the system output remains constant over time, the equation for LCOE reduces to

$$
\mathrm{LCOE}=(\mathrm{TLCC} / \mathrm{Q})(\mathrm{UCRF}) \text {. }
$$

where TLCC is the total life-cycle cost, $\mathrm{Q}$ is the firm's output, and UCRF is the uniform capital recovery factor. ${ }^{?}$

\section{Levelization}

Levelization is a technique that is commonly used in the utility industry to compare equivalent annual payment streams among alternatives facing the decision maker. The levelization process is essentially the same as previously described for the levelized cost of energy. That is, cash flows are discounted to their present value, then are levelized by multiplying the present value by the UCRF. A uniform payment stream, escalating at a constant rate $(\Delta \mathrm{P})$, can be levelized through the following single equation that combines the present value and the capital recovery factor calculation:

$$
L C=X_{0}+\sum_{n=1}^{n} X_{1} \frac{k\left(1-k^{n}\right)}{1-k} U C R F
$$

where LC is the levelized cost, $X_{l}$ is the cash flow to be levelized, $k$ equals $[(1+\Delta P) \div(1+d)], d$ is the discount rate, $\mathrm{n}$ is the number of time periods, and UCRF is the uniform capital recovery factor. In the previous expression, it is assumed that the price escalation is measured in the same type of dollars (i.e., either constant or current) as is used for the discount rate, $d$. Note that if there is no escalation in price (i.e., $\Delta P=0$ ), then $L C=X_{\text {. }}$.

The uniform capital recovery factor $(U C R F)=d(1+d)^{n} \div\left[(1+d)^{2}-1\right]$. 
The effect of the levelization of a cash flow is illustrated in Figure 4-2.

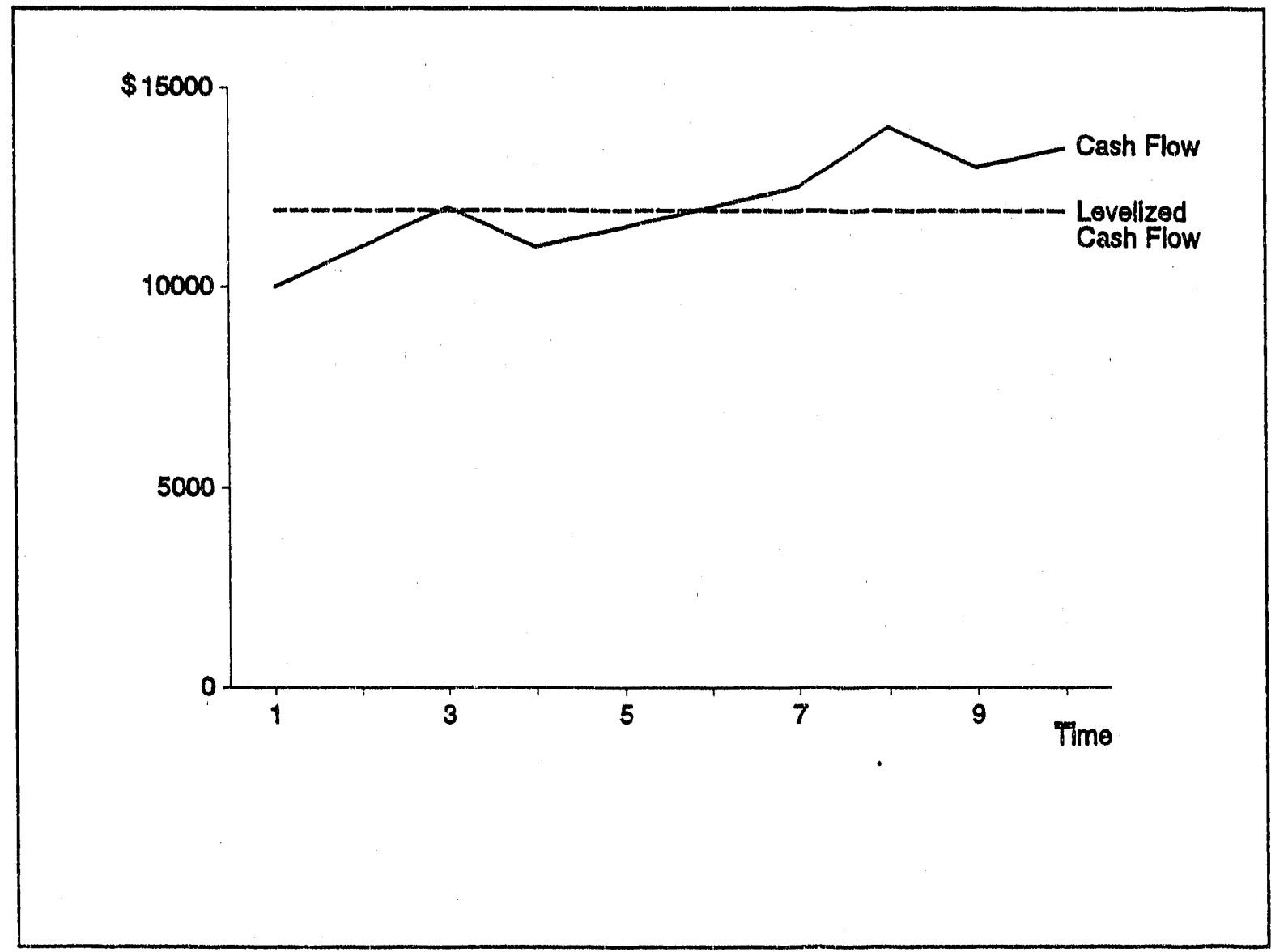

Figure 4-2. Comparison of a cash flow with a levelized cash flow

\section{Revenue Requirements}

Another method commonly used by the utility industry to examine investment alternatives is the revenue requirements method. The revenue requirements method calculates the amount of revenues necessary to meet all costs and achieve a certain preset after-tax rate of return. The revenue requirement method examines the various elements of the cost of service. These elements include carrying charges and expenses. Carrying charges include book depreciation, property and income taxes, return on equity, return on debt, and insurance. Expenses include fuel, operating and maintenance expenses (EPRI 1987). This costing method is well known and described in the EPRI technical assessment guide (TAG).

Businesses apply the revenue requirement method to project costs over the investment's useful life. The general decision rule for utilities is to choose the alternative for which the present value of the multiperiod 
investment revenue requirement is the lowest (Charles River Associates 1986). The basic formulation of the multiperiod investment required revenues approach (in vector form, i.e., $I \equiv\left[I_{1}, I_{2}, \ldots, I_{l}\right]$ ) can be stated as follows:

$$
\begin{gathered}
\operatorname{PV}(R R)=P V(C)+P V(E) \\
\operatorname{PV}(C)=P V(I)+P V(T) \\
P V(T)=\frac{\tau}{(1-\tau)}\left[(I)-P V\left(D_{r}\right)-P V\left(\mathrm{iB}_{0}\right)^{\prime}\right]
\end{gathered}
$$

where the present value of the revenue requirements (PV[RR]) is equal to the present value of the capital outlays (PV[I]), plus the present value of taxes (PV[T]), plus the present value of the costs of business (PV[E]). If the utility always has taxable income to offset tax assessment, the present value of income taxes is a function of the tax rate $(\tau)$, the present value of the capital outlays (PV[I]), the present value of he depreciation allowance $\left(P V\left[D_{\tau}\right)\right]$, and present value of the interest expense $\left(\mathrm{iB}_{0}\right) .^{8}$

\section{Internal Rate of Return}

The internal rate of return provides information on internally funded projects. This information can be used to decide whether investment funds should be spent internally or if the funds could provide a better rate of return elsewhere. In general, the internal rate of return (IRR).for an investment is the rate that sets the net present value of a revenue stream equal to zero. The internal rate of return analysis allows for the comparison of a wide variety of investment activities. For example, a company may wish to know whether or not it is profitable to engage in a business activity itself or to employ $n$ outside firm (Palm and Qayum 1985). More specifically, IRR is developed as a measure of merit in the FA\$T 123: Financial Analysis Standard program adopted by the California Energy Commission and preliminarily used to review policy options by NREL. IRR can be expressed as

$$
\text { IRR: } \quad 0=N P V-\sum_{t=0}^{N} \frac{R_{t}}{(1+d)^{t}}
$$

where NFV is the net present value of the capital investment, $R_{t}$ is revenue received at time $t$, and $d$ is the discount rate (Short 1983).

There are two areas of concern in the use of the internal rate of return. First, it is possible to be facid with the situation where multiple internal rates of return occur (these are also known as roots). This occurs when some of the future revenue flows are negative. Imaginary roots can occur when future revenues vary significantly (Palm and Qayum 1985). Second, internal rate of return analysis does not consider any tine dimension. For example, two mutually exclusive investment projects with an internal rate of return of $17 \%$ are considered equal. If two projects have different lengths (e.g., 20 years for project $\mathrm{A}$ and 3 years for project $\mathrm{B}$ ) a decision maker might not consider the two projects as equals ard

${ }^{8}$ For the complete mathematical derivation of the results, please see Charles River Associates Inc, Capital Budgeting for Utilities: The Revenue Requirements Method, EPRI research project EA-4879, 1920-3-1, Palo Alto: EPRI, 1986, p. 1-1, 1-26. 
not be indifferent between $A$ and $B$. That is, an investor may find a sustained 20-year revenue stream more desirable than a 3-year payment flow.

\section{Simple Payback Period}

The most common form of payback analysis is simple payback. Simple payback is the number of years necessary to recover the cost difference between the investments under consideration. The simple payback (SPB) can be expressed as

$$
S P B=\frac{\sum_{n=1}^{n} \Delta K_{n}}{\sum_{n=1}^{n} \Delta S_{n}}
$$

where SPB is the minimum number years required for the nondiscounted sum of annual savings to equal the nondiscounted incremental investment costs. $\Delta \mathrm{K}$ is all of the incremental investment costs (including incremental finance charges) nondiscounted. $\Delta S$ is the nondiscounted sum value of the annual savings net of future annuial costs.

The strength of the simple payback method is that it is easy to understand and calculate. Consequently, SPB is sometimes used as a default parameter in some logistic formulations. The drawback to the simple payback method is that it ignores the time value of money. That is, the use of simple payback implies that there are no opportunity costs to the investor or the investor's discount rate is zero (Ruegg 1987).

\section{Discounted Payback Period}

The discounted payback period is the number of years necessary to recover the incremental cost difference between the investments under consideration. The discounted payback (DPB) can be expressed as:

$$
D P B=\frac{\sum_{n=1}^{n} \Delta I_{n}}{(1+d)^{n}} \div \frac{\sum_{n=1}^{n} \Delta S_{n}}{(1+d)^{n}}
$$

where DPB is the minimum number of years required for the discounted sum of annual net savings to equal the discounted incremental investment costs. $\Delta \mathrm{I}$ is all of the incremental investment costs, $\Delta S$ is all of the annual savings net of future annual costs (i.e., $\Delta S$ equals the incremental energy costs plus incremental non-fuel operation, maintenance, and repair costs plus incremental replacement costs minus the incremental salvage costs), and $d$ is the discount rate (Ruegg 1987).

The discounted payback differs from the simple payback in that the analysis uses the present values of the changes in investments and savings. Thus, the discounted payback addresses the criticism of the simple payback's disregard for the time value of money (Brown and Yanuck 1980). If the project under analysis is a federal project that will be owned by the federal government, then taxes and tax credits should not be considered (as the federal government does not tax itself). However, if the analyst is evaluating a project from the viewpoint of the private (i.e., taxable) sector, then taxes and tax credits must be considered. Tax credits represent annual savings and additional property taxes represent additional annual costs. Future property taxes should be based on depreciated values and, if discounted payback is used, discounted. 


\section{Evaluation}

An advantage to cost models is that the cost factors can be specified in a straightforward manner (Raju and Teotia 1985). The cost models take advantage of all the price/cost information available in the market. As such, to the extent that the price/cost reflects the level of information in the marketplace, the cost models can incorporate the market's information on the product or technology.

There are three areas of concern in cost models. First, cost models usually adopt a cost function and then act as if this cost function is the sole determinant of market behavior. As such, cost models do not fully consider other aspects of the decision-making process. Two examples are non-priced environmental costs and information not fully assimilated in the marketplace. Second, the costing methods usually employed are by and large deterministic. For example, Mitre has used a logistic function with the ratio of a conventional system to a solar energy system's life-cycle cost as one of its explanatory variables in measuring market penetration (Rebibo et al. 1977 and EPRI 1982). Formal uncertainty analysis is difficult to accomplish in deterministic models. However, the market shares of the levelized cost of energy and required revenues cost models can be represented in terms of a distribution that incorporates a certain degree of uncertainty in the cost estimate (Raju and Teotia 1985). Third, cost models require data on the product or technology's associated costs. In some instances, cost models would require estimates of future costs of new products or technologies that have been in existence for only a short time. The degree of potential variability between the actual costs of a new technology and the future cost estimates could be great. 


\section{Section 5: Diffusion Models}

Diffusion models represent a major segment of the market penetration modeling literature and activity. As such, diffusion models will be exanined in detail. Diffusion models ${ }^{9}$ estimate the degree of entry of a new product into the marketplace. The discussion on diffusion models addresses the following models:

- Bass (1969)

- Fourt and Woodlock (1960)

- Mansfield (1961)

- Blackman (1974)

- Fisher and Pry (1971)

- Kalish (1985)

- Kalish and Lilien (1986).

In general, diffusion models are composed of two segments, innovators and imitators. Innovators are individuals who are the first to spontaneously adopt new technologies. Here, spontaneous means that the innovators are not influenced by previous adopiers but rather by some other external change agent, such as advertising (EPRI 1991). The imitator segment is influenced by the number of people who have already purchased the product or technology. This segment will increase relative to the number of innovators over time (Teotia and Raju 1986). The imitators are said to be influenced incernally. Thus, innovators are influenced by mass-media communications (external) and initators are influenced by wordof-mouth communications (internal) with those who already have purchased the product (Lekvall and Wahlbin 1973). In essence, the model implicitly assumes an information transfer between the innovators and the imitators (Teotia and Raju 1986).

\section{Bass Model}

The Bass model (1969) is a generalized form that can be used to illustrate other commonly used diffusion models. Moreover, by relaxing some of the usual restrictions made on diffusion models, recent developments in diffusion modeling can be demonstrated. The basic diffusion model can be expressed as

$$
n(t)=\frac{d N(t)}{d t}=p[M-N(t)]+\frac{q}{M} N(t)[M-N(t)]
$$

\footnotetext{
The discussion of diffusion models focuses directly on diffusion models and only addresses econometric techniques tangentially. In diffusion models, econometrics is used as a tool to obtain parameter estimates. A variety of methods (e.g., ordinary least squares, maximum information likelihood, and nonlinear least squares) have been used to estimate the same or similar parameters. Therefore, econometrics is a peripheral issue for diffusion models. Econometric techniques are discussed later and will include issues relevant to diffusion models.
} 
where $n(t)$ is the rate of adopters at time $t, N(t)$ is the cumulative number of adopters, $M$ is the ultimate number of adopters, $p$ represents the adoptive influence that is independent of prior adoptions, and $q$ represents the adoptive influence that depends on imitation or learning (Mahajan, Muller, and Bass 1990).

The term $p[M-N(t)]$ in the previous equation represents the number of purchasers who are not influenced by other individual's purchase decisions. The term $q / M N(t)[M-N(t)]$ represents the number of purchasers who are swayed by the number of previous buyers. The terms $p$ and $q$ are referred to as the coefficient of innovation and the coefficient of imitation, respectively (Bass 1969). Typically, $p$ and $\mathrm{q}$ are assumed to be constants. The adopter distribution assumes an initial pM level of purchasers who buy the product at the beginning of the process. There exists a point $T^{*}$, which indicates the maximum adoption level. $T$ is also the inflection point of a sigmoid (S-shaped) cumulative adoption function. The cumulative adoption function is symmetric around $T^{*}$ such that the interval range 0 to $T^{*}$ is a mirror image of the range T to 2T (Mahajan, Muller, and Bass 1990).

The discussion of sigmoid functions, points of inflections, and symmetry can be somewhat mystifying and obtuse. Therefore, Figure 5-1 is included (a graphical representation of the Bass model) to help clarify the discussion. ${ }^{10}$ Figure 5-1 consists of three graphs. Figure 5-1(a) is a graphic representation of the typical shape of the Bass model. The graph is divided into two areas: (1) the amount of adoption attributed to individuals influenced by external sources (innovators), and (2) the amount of adoption attributed to individuals influenced by internal factors (imitators).

Figure 5-1(b) is composed of two graphs. The first graph illustrates the inflection point and the symmetry range $\left[0-T^{+}, T-2 T\right]$. The second graph illustrates a sigmoid cumulative adoption function. The S-shaped nature of the cumulative adoption function is a commonly made assumption.

Most diffusion models use, some form of the sigmoid shape. The reason for the use of an S-shaped curve is usually given in terms of market evolution. In the beginning, initial market penetration is slow. This is due to (among other factors) the lack of information, bottlenecks, and buyer uncertainties. As these factors are effectively addressed, and innovators interact with imitators, the growth rate in the intermediate stage accelerattes. Finally, the product approaches market saturation, and the growth rate declines (Teotia and Raju 1986). Although most diffusion models use an S-shaped function, it is not universally true. Alternative specifications are used.

The main criticism of smooth symmetric functions is that there exists no unquestionable, logically intuitive reason why the functions should be symmetric. It is given (i.e., assumed in the model) that there are two distinct adopter groups. These two groups are assunned to consist of different individuals who are affected by different factors and behave differently. The basic argument is that symmetry is a mathematical convenience and does not portray a reflection of reality.

\section{Fourt and Woodlock Model}

One way to affect the shape of the market adoption path is by adjusting the coefficients of innovation and imitation. The coefficients of innovation (p) and imitation ( $q$ ) have a direst effect on the diffusion model's estimation of mariket penetration. If we assume that the coefficient of imitation equals zero ( $q$ $=0$ ), then the diffusion process excludes imitators and is based purely on the innovation effect; this

${ }^{10}$ Figure 5-1 was originally created by Mahajan, Muller, and Bass (1990) and is reproduced with the consent of the American Marketing Association. 
(a)

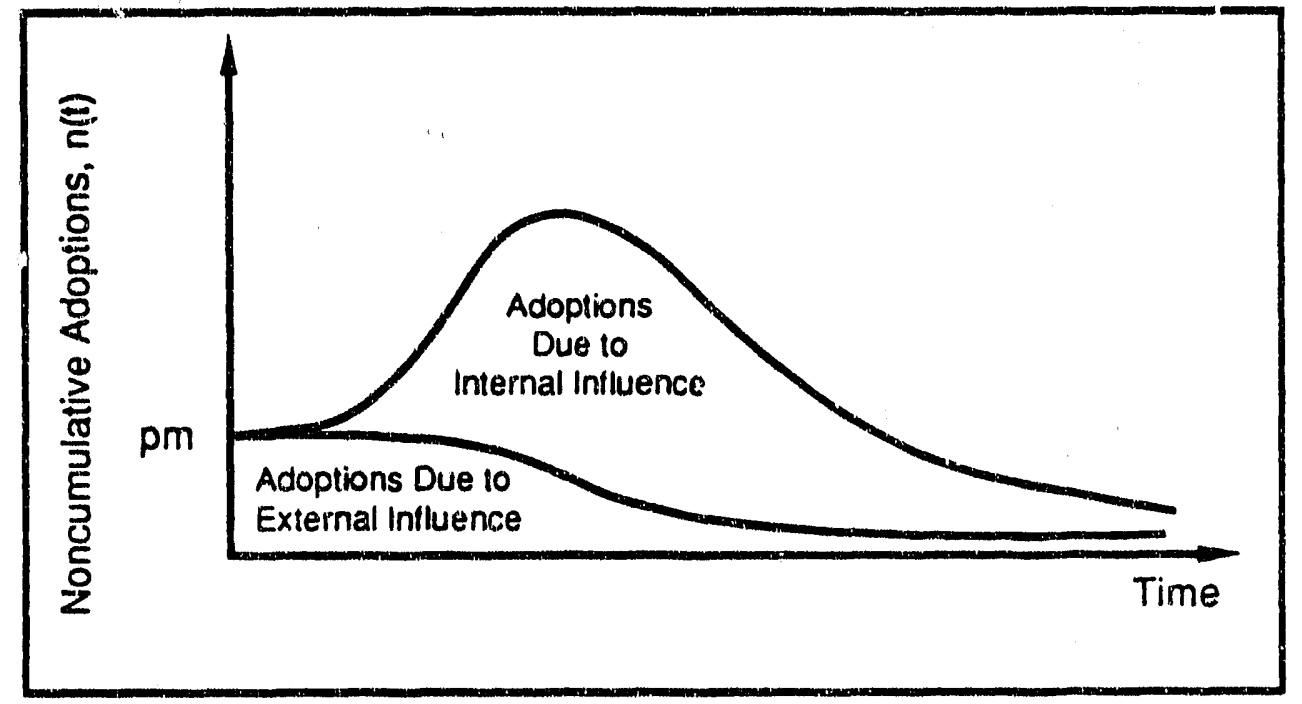

(b)
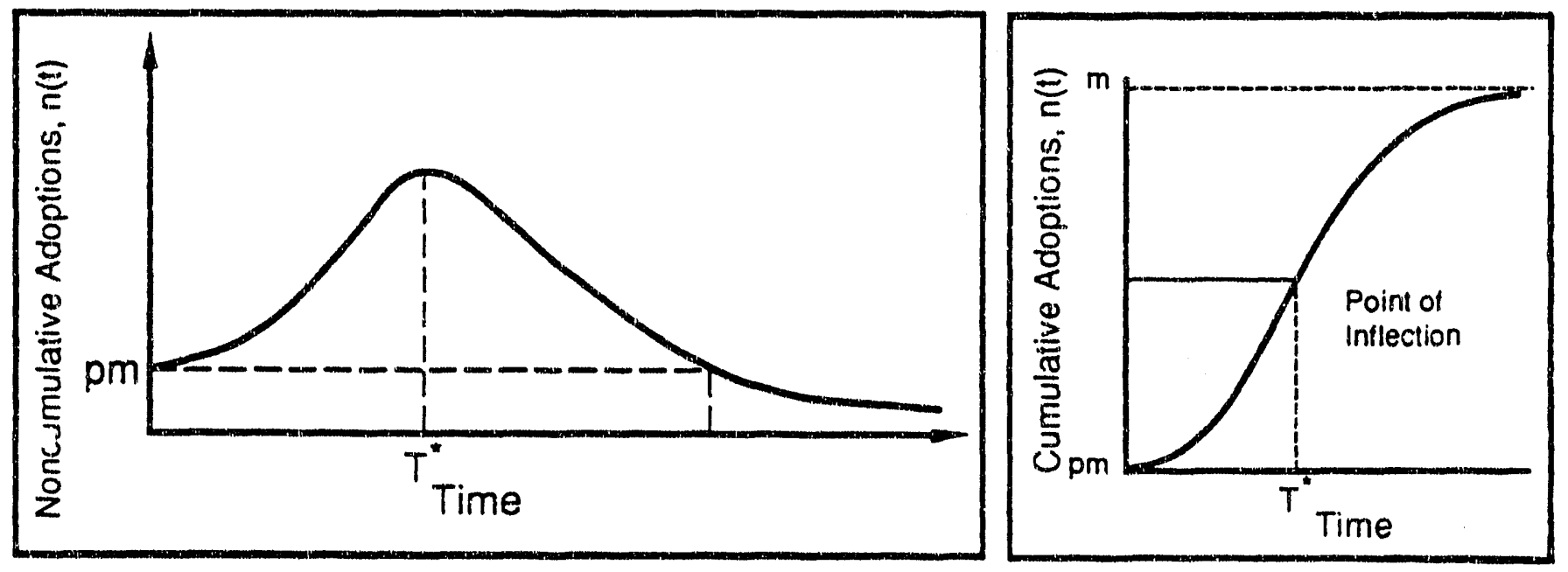

1990. Used with the permission of the American Marketing Association.

Source: Mahajan, Muller, and Bass 1990.

Figure 5-9. The Bass new product diffusion model: (a) adoptions due to external and internal influences in the Bass model; (b) analytical structure of the Bass model. 
model is similar to the Fourt and Woodlock (1960) model. Given the mathematical construct of the Fourt and Woodlock model, the number of innovators at time $t$ is proportionally related to the potential number of adopters remaining $p(M-N[t])$. This results in a concave exponential growth curve, which asymptotically approaches a defined market penetration limit (Teotia and Raju 1986).

\section{Mansfield Model}

If the coefficient of innovation equals zero $(p=0)$, then the Bass model becomes similar to Mansfield's (1961) internal-influence model, and the diffusion process is completely described by the imitation effect $\{(q / M) N(t)[M-N(t)]\}$ (EPRI 1991). Mansfield used his model to effectively consider the market penetrations of technological innovations in the iron and steel industry, railroads, and the brewing industry. The Mansfield model also possesses an S-shaped symmetric cumulative adoption function (Philipson 1978). Thus, if the communication or information network is dominated by internal sources, the diffusion curve will tend toward a logistic function. Whereas, if the communication or information network is external, the diffusion curve will approximate a modified exponential function. This implies that, unless there is reliable a priori information available about the relative strength of internal and external influences, care should be taken in the specification of the shape of the diffusion curve (Lekvall and Wahlbin 1973).

\section{Blackman Model}

Let us now turn to modifications to the basic diffusion models. Blackman (1974) modified Mansfield's model and estimated the new technology's market share directly. Blackman successfully applied the logistic model to the acceptance of new transportation systems, nuclear power, and automobile components (Philipson 1978). Blackman employed the following expression:

$$
\ln \left(\frac{m s_{t}}{\left(L-m s_{t}\right)}\right)=-\ln \left(\frac{L}{N_{0}}-1\right)+\gamma\left(t-t_{1}\right)
$$

where $\mathrm{ms}_{\mathrm{t}}$ is the market share of a new technology at time $\mathrm{t}, \mathrm{L}$ is the long run upper limit of the market share, $N_{0}$ is the market share when $t=t_{1}, \gamma$ is a substitution rate constant, and $t_{1}$ is the year the new product obtained a market share. The previous equation can be rewritten as

$$
\ln \left(\frac{\mathrm{ms}_{\mathrm{t}}}{\left(\mathrm{L}-\mathrm{ms}_{\mathrm{t}}\right)}\right)=\mathrm{C}_{1}+\mathrm{C}_{2}\left(\mathrm{t}-\mathrm{t}_{1}\right)
$$

where $C_{1}$ and $C_{2}$ are constants.

The main attractions of this approach are that the estimation of the coefficients $C_{1}$ and $C_{2}$ are straightforward ${ }^{11}$ and that the historical data reçuirements are not extensive. The parameters were estimated using an ordinary least squares econometric technique. Predictions can be made after a new technology has captured a market share as little as $2 \%$ (Teotia and Raju 1986).

\section{Fisher and Pry Model}

A variation of the Mansfield and Blackman approach was developed for two technologies by Fisher and Pry (1571). Fisher and Pry expressed their technology substitution model as being dependent on

\footnotetext{
"Econometric techniques are discussed in the last section of this report.
} 


$$
\frac{f}{(1-f)}=\exp \left[2 \delta\left(t-t_{0}\right)\right]
$$

where $\mathrm{f}$ is the market share, $\delta$ is one-half the annual fractional growth in the early years, and $t_{0}$ is the time when market share equals $50 \%$ (Teotia and Raju 1986).

Fisher and Pry applied their approach to a number of industries. For example, they studied synthetic versus natural fibers, plastic versus leather, synthetics versus natural ruk er, and plastic versus metal in cars. An interesting conclusion of Fisher and Pry's work was that this model indicates that once a technology has $5 \%$ of the market, it is highly probable that the process will continue until the new technology completely replaces the former technology.

This result followed from Fisher and Pry's assumed pattern of market penetration ${ }^{12}$ and is sufficiently starting to merit additional attention. In order to understand how Fisher and Pry arrived at their conclusion, it is necessary to examine how the cumulative number of adoptions (N[t]) is functionally related (via $F[t]$ ) to the market potential (M). Using the generalized Bass (1969) model, this can be expressed as

$$
N(t)=M F(t)
$$

If we assume that $M$ is a constant ${ }^{13}$ (as is assumed in most diffusion models using the generalized Bass form) then we can differentiate $F(t)$ with respect to time and arrive at

$$
M \frac{d F(t)}{d t}=[p+q F(t)][M-M F(t)]
$$

where $p, q, F(t)$, and $M$ are the same as previously defined. Dividing through by $M$ we obtain (EPRI 1991)

$$
\frac{d F(t)}{d t}=[p+q F(t)][1-F(t)]
$$

The previous equation indicates that the rate of change in relative cumulative adoption is a function of $p, q$, and $F(t)$ and is independent of the market size (EPRI 1991). Thus, the Bass model assumes that the market potential is set at the time of introduction and remains fixed (Mahajan and Peterson 1978). The independence of the curnulative adoption to market size is a criticism that has been repeatedly leveled against the standlard diffusion models.

Theoretically, there is no reason for a fixed adopter population. A more reasonable assumption would be to assume a changing adopter population (Mahajan, Peterson, Jain, and Malhotra 1979). For example, a product's effective geographical boundary can change over time. A product from one region can expand into another "untapped" adjacent region and capitalize on positive word-of-mouth communication across regions. This effect is referred to as the "neighborhood effect" (Mahajan, Muller, and Bass 1990).

\footnotetext{
${ }^{12}$ Fisher and Pry referred to market penetration as market substitution.

${ }^{13}$ This assumption will be relaxed later in this section.
} 


\section{Kalish Model}

Another objection to the fixed potential adopters assumption is that the adopter population could be affected by price and internal communications (Kalish 1985). Kalish's diffusion model illustrates the relaxation of the restrictive fixed potential adopter population assumption and expresses the potential adopter population $\mathrm{m}(\mathrm{t})$ as

$$
m(t)=m_{0} \exp \left[-a P(t) \frac{b+1}{b+\frac{N(t)}{m_{0}}}\right]
$$

where $a$ and $b$ are constants, $m_{0}$ is the initial potential adoption population, $P(t)$ is the price at time $t$, and $\left[(b+1) /\left(b+N(t) / m_{0}\right)\right]$ is the internal effect on the adoption population.

\section{Kalish and Lilien Model}

In addition to questioning the assumption on fixed potential adoption populations $\mathrm{M}$, modelers questioned the assumption of a constant coefficient of innovation (p), and the positive assumption on the imitation influence (q). Kalish and Lilien (1986) developed a model that treated adoption populations as a function of price, related the innovation coefficient (p) to the level of advertising, and allowed for a qualityvarying internal feedback (i.e., positive or negative). The Kalish and Lilien model that incorporated advertising and the possibility of both positive and negative internal feedback is

$$
S(t)=[N(t) h P(t)-X(t)]\{R[A(t)]+\beta Q(t)\}
$$

where $X(t)$ is the cumulative adopters at time $t, S(t)$ is the new adopter at time $t$ (i.e., $X[t]-X([t-1]), N(t)$ is the market potential when price equals zero, $P(t)$ is price as a function of time, $h$ is the fraction of market potential that finds price $(P[t])$ acceptable, $A(t)$ is the external information level in the marketplace (e.g., advertising and comnunication effects), $Q(t)$ is the perceived product quality at time $t, R[A(t)]$ is the market response at $t$ to $A(t)$, and $\beta$ indicates the market response to $Q(t)$. Kalish and Lilien applied this approach to a proposed photovoltaic program sponsored by the U.S. Department of Energy.

\section{Evaluation}

As a general statement, the inclusion of price or a cost-oriented variable affecting the adoption of a new technology is important and merits discussion. First, this allows the cost models presented previously to be directly incorporated into the diffusion model. Second, in models that use a logistic function to e.timate market penetration, it is important to have the behavioral response based on market indicators of competitiveness (e.g., the new technology's normalized revenue requirement) and not on just time.

Market competitiveness variables arrive at market penetration estimates based on straightforward, competitive market criteria; whereas a time variable represents a collection of undefined factors that move relentlessly forward, reflecting an unswerving, positive trend. In his review of solar energy, market penetration models, Warren (1980) states:

The assumptions underlying these two distinct representations of a logistic curve are subtle but important. If the horizontal axis measures economic competitiveness, then the behavioral lag represented by the logistic curve is based upon changing economic competitiveness. When the solar technology is only marginally better than the conventional technology, a few innovators will adopt the solar technology. However, as the solar technology becomes more 
clearly economically superior, a "bandwagon" effect occurs which gradually dissipates as the majority of the market is captured.

...so that its potential market is defined as that portion of the total market in which it can be competitive. On the other hand if time is used as the measure on the horizontal axis, then the behavioral lag is due to combinations of several factors, including the economic advantage of the solar energy technology, the initial uncertainty, and the extent of the commitment required to adopt the solar energy technology....thus the potential market is the total market. This distinction is important because almost all empirical evidence in support of the logistic curve relates market penetration to time rather than to economic competitiveness, thus undermining the degree of confidence one can place in solar energy market penetration analysis.

Modelers still continue to use Bass' basic model structure, focusing their efforts on making refinements in the model's specification, components, and assumptions. The critical components of diffusion models, in a general sense, are the specification of the potential adopters $(M)$, the coefficient of innovation (p), the coefficient of imitation (q), and the function that defines the product's diffusion over time (F[t]). $M$, $p$, and $q$ have already been discussed; let us now focus on $F(t)$.

Cornmon functional forms for $F(t)$ are the cumulative normal, logistic, lognormal, and Gompertz functions ${ }^{14}$ (Teotia and Raju 1986). One of the main areas of interest is how $F(t)$ will perform over time (i.e., dF/dt). Historically speaking, there are three major criticisms of diffusion models. Diffusion models have been faulted for fixed coefficients of imitation, the maximum rate of penetration occurring at 0.50 of the market and an arbitrary symmetric functional form of $\mathrm{dF}(\mathrm{t}) / \mathrm{dt}$ (Easingwood, Mahajan, and Muller 1983). For ease of comparison, a list of some of the functional forms of various models are presented in Table 5-1.

Previously in this section, a model was presented that allowed both the coefficient of innovation and the coefficient of imitation to vary. Table 5-1 clearly indicates that concerns about artificial restriction for symmetry and midpoint inflections are not universally present for diffusion model $\mathrm{dF}(\mathrm{t}) / \mathrm{dt}$ equations. Consequently, although the three concerns were validly held in the past, the current literature has revealed that these problems have been addressed.

Even though the problems of restrictive assumptions on adopter populations and the coefficients of innovation and imitation have been addressed in the literature, other problems remain. The discussion of the remaining issues focuses on three problem areas. First, the diffusion of an innovation $i$. independent of all other innovations. Moreover, diffusion models do not consider the simultaneous diffusion of multiple innovations (Mahajan and Peterson 1978). This is a critical shortcoming if the adoption of one innovation depends on the diffusion of another innovation. An example is compact disc software and hardware (Mahajan, Muller and Bass 1990). It is obvious that the rate of diffusion of compact discs is related to the already purchased compact disc players. ${ }^{15}$ However, standard diffusion models would ignore this linkage.

${ }^{14}$ The Gompertz function is considered less restrictive than the logistic and lognonnal functions (Lakhani 1979).

${ }^{15}$ Another exarnple would be the classic razor and razor blade marketing strategy. 
Table 5-1. Alternative Sperifications for F(t)

\begin{tabular}{|c|c|c|c|}
\hline Model & $\begin{array}{l}\text { Model Equation } \\
\text { (dF/dt) }\end{array}$ & Inflection Pt. (T) & Symmetry about $T^{*}$ \\
\hline Bass (1969) & $(p+q F)(1-F)$ & $0.0-0.50$ & $\begin{array}{l}\text { Nonsymmetric, } \\
\text { symmetric } 0-2 \mathrm{~T}\end{array}$ \\
\hline $\begin{array}{l}\text { Chow (1965) } \\
\text { Gompertz Curve }\end{array}$ & $(\mathrm{Qf})[\ln (1 / \mathrm{F})]$ & 0.37 & Nonsymmetric \\
\hline Mansfield (1961) & $(\mathrm{Qf})(1-\mathrm{F})$ & 0.50 & Symmetric \\
\hline Floyd (1962) & $(Q f)(1-F)^{2}$ & 0.33 & Nonsymmetric \\
\hline $\begin{array}{l}\text { Sharif and Kabir } \\
\text { (1976) }\end{array}$ & $\frac{(O f)(1-F)^{2}}{[1-F(1-\sigma)]}$ & $0.33-0.50$ & $\begin{array}{l}\text { Symmetric or } \\
\text { nonsymmetric }\end{array}$ \\
\hline Jeuland (1981) & $(p+q F)(1-F)^{1+\gamma}$ & $0.0-0.50$ & $\begin{array}{l}\text { Symmetric or } \\
\text { nonsymmetric }\end{array}$ \\
\hline $\begin{array}{l}\text { Easingwood, } \\
\text { Mahajan, and Muller } \\
\text { (1981) }\end{array}$ & $\left(p+q F^{0}\right)$ & $0.0-1.0$ & $\begin{array}{l}\text { Symmetric or } \\
\text { nonsymmetric }\end{array}$ \\
\hline $\begin{array}{l}\text { Easingwood, } \\
\text { Mahajan, and Muller } \\
\text { (1983) }\end{array}$ & $\left(p+q F^{D}\right)(1-F)$ & $0.0-1.0$ & $\begin{array}{l}\text { Symmetric or } \\
\text { nonsymmetric }\end{array}$ \\
\hline Nelder (1962) & $(\mathrm{qF})\left(1-\mathrm{F}^{\phi}\right)$ & $0.0-1.0$ & $\begin{array}{l}\text { Symmetric or } \\
\text { nonsymmetric }\end{array}$ \\
\hline $\begin{array}{l}\text { Von. Bertalanffy } \\
(1957)\end{array}$ & {$[q /(1-\theta)] F^{\theta}\left(1-F^{1-\theta}\right)$} & $0.0-1.0$ & $\begin{array}{l}\text { Symmetric or } \\
\text { nonsymmetric }\end{array}$ \\
\hline
\end{tabular}

Second, diffusion models are demand models. There are no supply restrictions. Consequently, the model assumes that the unmet demand generates a waiting line of willing adopters (Simon and Sebastian 1987). This may or may not be the case. Supply restriction due to lack of production capacity or inefficient distribution systems may take a significant time to alleviate. The effect of long delays on the potential customer's desire to purchase new technologies may be negative. As such, customers may not be so willing to wait, as Simon and Sebastian hypothecate.

Finally, diffusion models typically assume the nature of the innovation does not change over time. Diffusion models typically freeze the new technology's attributes at the time of the product's introduction. This implies a static technology. It also denies the producers the ability to detect market reactions and move effectively to address the market's concerns (Mahajan, Muller, and Bass 1990).

Diffusion models are well known and are currently making theoretical advancements in the literature. These models have been used successfully in the past, but not always. Diffusion models appear to present the reatest advantage for market penetration forecasting when little data are available (EPRI 1991). 
Although the data needs may not be as great as for other models, diffusion models do require data for parameter estimation. This is particularly the case for the number of potential adopters and the coefficients of innovation and imitation. Data on these parameters can be obtained in a variety of ways. Lawrence and Lawton (1981) suggest obtaining this information by using subjective judgment, as does Mahajan and Sharma (1986). Other authors suggest more standard approaches such as econometric estimation and Bayesian infirence (Srinivasan and Mason 1986).

Diffusion models create point estimates and therefore are deterministic. Consequently, the analyst cannot treat uncertainty explicitly (Raju and Teotia 1985). Therefore, confidence intervals around the model's results are not available using standard procedures. 


\section{Section 6: Time-Series Models}

Time-series models are the logical extension of the following supposition: given that a technology's history spans a workable length of time, an analyst might reasonably entertain the possibility of inferring from its history the path that the technology is most likely to follow in the future (Nelson 1973).

It may not be possible to adequately explain the behavior of a time function $\left(y_{j}\right)$ by relating $y_{t}$ to economic variables. This is often the situation when economic data are not available or when the economic data are of sufficiently poor quality that analytically derived results would be suspect. Thus, it may not be desirable to model $y_{t}$ within a structural econometric model (Pindyck and Rubinfeld 1981). In such a case, time-series analysis may provide a useful alternative. Moreover, time-series analysis can be a useful comparison tool for other analytical methods, such as simultaneous equation systems (Chow 1983).

Within a stable system, a number of time-series models could effectively describe the past behavior of time function $y_{t}$ and be useful in predicting the future behaviors of the same variable. For the purposes of this report, the following five time-series approaches are discussed:

- Simple extrapolation models

- Autoregressive models

- Moving average models

- Mixed autoregressive and moving average models

- Autoregressive integrated moving average models.

Not discussed are the more advanced time-series models such as spectral analysis or time-varying coefficients and their application to time-series modeling. ${ }^{16}$ The primary reason for the exciusion of the spectral analysis and other advanced models is that these models are data intensive. That is to say, they require extensive data sets. Unfortunately, extensive time-series data sets are not common in the market penetration analysis of new energy technologies. Consequently, these models are not included in this report. The simple extrapolation and autoregressive models can be executed on spreadsheet software (e.g., Lotus 123 and Excel), but the more technically sophisticated models will require more advanced software such as SAS or TSP.

\section{Simple Deterministic Extrapolation Models}

The discussion on simple extrapolation models focuses on two approaches: (1) linear trends and (2) exponential growth models. These are two commonly used models in market penetration analysis. The discussion on linear trends also shows how the linear trend model can be simply extended to address simple nonlinear (i.e., quadratic and polynomial) trends. ${ }^{17}$ These models are usually deterministic. Deterministic models provide point estimates when used for forecasting purposes. Therefore, deterministic models provide no information on the error structure around these forecasted estimates.

\footnotetext{
${ }^{16}$ For those interested in spectral analysis or time-varying coefficients, please see Chow (1983).

${ }^{17}$ Extrapolation methods can also be useful in estimating the values of missing observations in data sets.
} 


\section{Linear Trend Models}

The simplest extrapolation model is the linear trend model. If there is reason to believe that the time function $y_{t}^{18}$ increases by a constant amount for each time period, and it is believed that this trend will continue into the future, then the analyst can predict future values of $y_{s}$ by fitting a trend line to the relationship

$$
y_{t}=a_{0}+a_{1} t
$$

where $y_{t}$ is the value of $y$ at time $t, t$ is a time variable indicator, $a_{0}$ is a constant, and $a_{1}$ is the constant absolute relationship over time. The variable $t$ is referred to as a time variable indicator because $t$ is usually set to equal 0 in the base period and allowed to increase by 1 over each successive period $(t=$ $0,1,2,3, \ldots, T)$. In order to predict the value of $y$ one period in the future $(T+1)$, the analyst simply calculates

$$
y_{T+1}=a_{0}+a_{1}(T+1)
$$

In certain instances, the functional relationship $y_{t}$ is nonlinear. In these situations, the analyst may find a quadratic specification provides a more accurate description of $y_{t}$ behavior over time. The linear extrapolation method can be extended to a nonlinear quadratic method by simply specifying the relationship as

$$
y_{1}=a_{0}+a_{1} t+a_{2} t^{2}
$$

where $y_{t}$ is the value of $y$ at time $t, t$ is a time variable indicator, $a_{0}$ is a constant, $a_{1}$ is the constant relationship over time, and $a_{2}$ is the effect on $y$ from the square of the time indicator. This type of extrapolation can be extended to include higher order polynomials $\left(y_{t}=a_{0}+a_{1} t+a_{2} t^{2}+a_{3} t^{3}+\right.$ etc. with little difficulty.

\section{Exponential Growth Curves}

In market penetration analysis, it may be more reasonable to assume that $y_{t}$ increases at a constant percentage rate rather than at an absolute amount per period. ${ }^{19}$ If this is the case, then the linear trend model would severely underestimate the future values of $y$ after some time. To avoid this problem, the exponential growth curve method is used. ${ }^{20}$ The exponential growth curve method is specified as

$$
y_{t}=A e^{n}
$$

where $y_{t}$ is the value of $y$ at time $t, t$ is a time variable indicator, $A$ and $r$ are constants chosen to maximize the correlation of the relation with $y_{t}$ over time. If one chooses the exponential growth curve method to forecast, then a forecast of one time period into the future would be given by

${ }^{18} Y_{\imath}$ could be defined to be new technology sales or total sales in the market.

${ }^{19}$ Note: this is not true for higher order polynomials.

${ }^{20}$ Another approach employs a linear model in a double logarithmic specification, i.e., a logarithmic autoregressive trend model $\log y_{t}=a_{0}+a_{1} \log y_{t-1}$ (Pindyck and Rubinfeld 1981). Autoregressive models are discussed later in this section. 


$$
y_{T+1}=A e^{r(T+1)}
$$

where $y_{T+1}$ is the value of $y$ at time $T+1, T+1$ is the time indicator one period in the future, and $r$ and A are defined the same as for equation (6-4) (Pindyck and Rubinfeld 1981).

\section{Stochastic Time-Series Models}

\section{Autoregressive Model}

Thus far, we have assumed that $y_{3}$ is only affected by time. The methods presented previously in this section imply that $y_{t}$ behaves mechanically over time-time being the only exogenous consideration. This implies that once the process has begun, it will continue to operate- $y_{t}$ continually and systematically responding to the passage of time. Individatis have argued that a more reasonable approach is to examine the economic variables based on the historical performance of the economic variable itself (Nelson 1973). The argument is basically that the factors that affected the economic variable in the past have been captured in the economic varlallie's market performance. It is then assumed that those factors, which affected the economic variable in the past, will continue to do so in the future. Thus, the argument goes, the future perforrance of an economic variable can be predicted from its past. This is particularly true for short-term forecasts (Juige et al. 1982). The argument is that structural changes are unlikely to occur in the brief time period under examination.

One method that uses the variable's past values is the autoregressive model (AR). The specification for the autoregressive model is

$$
y_{t}=\alpha_{1} y_{t-1}+\alpha_{2} y_{t-2}+\cdots+\alpha_{p} y_{t-p}+\dot{\varepsilon}_{t}
$$

where $y_{t-1}$ is the value of $y, i$ time periods in the past, $\alpha_{i}$ 's are the parameter estimates of the influence on $y_{t}$ from itself $i$ periods past, $\epsilon_{i}$ is the residuals or unexplained variations between what would be predicted by the equation and the actual $y_{i}$ values.

The model presented above is said to be of order $p$ because there are $y_{t . p}$ past values of $y_{t}$ used to explain the market performance of $y_{t}^{21}$. The number of past periods selected is determined by what is necessary in order to obtain random residuals, $\epsilon_{4}$. It is desired that the random residuals are serially independent and uncorrelated, having a mean value of zero and constant finite variance for all $t$ (Chow 1983). If the residuals possess these properties, then time-series analysts refer to the residuals as white noise ${ }^{22}$ (Judge et al. 1982). Notice that the autoregressive model $^{23}$ is no longer deterministic. The inclusion of the residual or error term has changed the modeling process from deterministic to stochastic.

\footnotetext{
${ }^{21}$ The accepted way to indicate an autoregressive model of order $p$ is $\operatorname{AR}(p)$. The $p$ coefficient estimates can be determined through the use of the Yule-Walker equations in a straightforward manner (Pindyck and Rubinfeld 1981). Moreover, autoregressive and moving average techniques are widely recognized, and direct parameter estimation is available via a variety of computer software packages (Judge 1982).

22If the residuals are normally distributed, then they are said to be Gaussian white noise,

${ }^{23}$ All subsequent models in this section are not deterministic.
} 


\section{Moving Averago Models}

In the moving average models (MA), the observations of $y_{t}$ are generated by a weighted average of the residuals or random disturbances $q$ periods in the past. ${ }^{24}$ As shown in the next equation, time-series moving average models focus on the behavior of the error term $\epsilon_{\mathrm{f}}$. The properties of the random disturbances or residuals $\epsilon_{\text {a }}$ are specified the same as those presented for the autoregressive model (Chow 1983). The moving average model assumes that the residuals are white noise and takes the form

$$
y_{t}=\epsilon_{t}+\beta_{1} \epsilon_{t-1}+\cdots+\beta_{q} \epsilon_{t-1}
$$

where $y_{t}$ is the value of $y$ at the $t$ time period, $\epsilon_{\mathrm{i} j}$ is the residuals, and $\beta_{j}$ 's are the parameter estimates of the influence of the $t-j^{\text {th }}$. residual on $y_{x}$.

\section{Mixed Autoregressive and Moving Average Models}

Combining the previous two models forms the mixed autoregressive and moving average model (ARMA). If the ARMA is of order $p$ in its autoregressive segment and of order $q$ in its moving average section, the model is denoted $\operatorname{ARMA}(p, q)$ and expressed as

$$
y_{t}=\alpha_{1} y_{t-1}+\cdots+\alpha_{p} y_{t-p}+\varepsilon_{t}+\beta_{1} \varepsilon_{t-1}+\cdots+\beta_{q} \varepsilon_{t-q}
$$

where $y_{t-1}$ is the value of $y$ in the $t-i^{\text {th }}$ time period, $\alpha_{1}$ 's are the parameter estimates of the influence on $y_{t}$ from itself $i$ periods ago, $\epsilon_{i}$ is the residuals, and $\beta_{j}$ 's are the parameter estimates of the influence of the $\mathrm{t}-\mathrm{j}^{\text {th }}$ residual on $\mathrm{y}_{\mathrm{t}}$ (Chow 1983).

\section{Autoregressive Integrated Moving Average Model}

The autoregressive integrated moving average model (ARIMA) is very similar to the ARMA process except that the dependent variable is differenced. Differencing is a straightforward process. The analyst simply takes the dependent variable at time $t$ and subtracts the dependent variable at $t$ minus one from it (i.e., $y_{t}-y_{t-1}$ ). The rernainder of the ARIMA technique remains the same as the ARMA process presented above. ARIMA models are typically denoted as ARIMA(p,d,q). The p represents the order of the autoregressive segment, $q$ represents the order of the moving average section, and $d$ represents the number of times the dependent variable has been differenced. A first differenced autoregressive integrated moving average model $\operatorname{ARIMA}(p, 1, q)$ may be written as

$$
w_{t}+\alpha_{1} w_{t-1}+\cdots+\alpha_{p} w_{t-p}+\epsilon_{t}+\beta_{t-1} \epsilon_{t-1}+\cdots+\beta_{q} \epsilon_{t-q}
$$

where $w_{t}$ is the first difference value of $y_{t}, \alpha_{i}$ 's are the parameter estimates of the influence on $w_{t}$ from itself $i$ periods past, $\epsilon_{i}$ is the residuals, and $\beta_{j}$ 's are the parameter estimates of the influence of the $t-j_{t h}$ residual on $w_{t}$.

Given that $w_{t}$ equals $y_{t}-y_{t-1}$, we can rewrite the above equation as

$$
y_{t}=y_{t-1}+\alpha_{1} w_{t-1}+\cdots+\alpha_{p} w_{t-p}+\varepsilon_{t}+\beta_{t-1} \varepsilon_{t-1}+\cdots+\beta_{q} \varepsilon_{t-q}
$$

where $y_{t}$ is the value of the dependent variable at time $t, w_{t}$ is the first difference value of $y_{t}$, and $\alpha_{i}$ 's, $\epsilon_{t}$, and $\beta_{j}$ 's are the same as previously defined (Box and Jenkins 1976).

${ }^{24}$ The accepted shorthand presentation of a moving average model of q periods in length is MA(q). 


\section{Evaluation}

Although the computations involved with stochastic time-series models can be involved, the approach's logic is straightforward. Basically, stochastic time-series models obtain their predictive power by fitting $y_{t}$ to a line of time-lagged dependent variables $\left(y_{t}\right)$, minimizing the size of the unexplained residuals while preserving the residual's randomness.

The main advantages of time-series models are that the methodology is well established and documented, and formal diagnostic tests exist (for the stochastic models). In addition, time-series models require data on only one variable. Thus, the data requirement for time-series models is less than that of econometric models. Econometric models use a number of explanatory variables, each explanatory variable requiring a comparable data set. However, a reliable historical data base on the dependent variable is critical for time-series analysis. Thus, the data requirements for time-series estimation may be such that time-series techniques may be unsuitable for estimating the market penetration of new technologies. That is, new technologies, which have been in existence for only a short time, do not possess a reliable historical data base (Raju and Teotia 1985).

Moreover, time-series analysis relies implicitly on the continuation of past structural behaviors. In essence, time-series models rely innately upon the status quo. The predictive power of time-series models rests upon past relationships continuing into the future. Thus, time-series models are frequently used for short-term analysis in which the structural factors are assumed to remain stable over the examined time period.

Because time-series models do not contain explanatory variables other than time, time-series models are limited in their explanatory power and predictive abilities. Time-series models typically perform poorly during times of exogenous changes in market factors or social infrastructure. This is of particular importance to the market penetration of RETs, because changes in tax codes, fuel prices, a utility's capacity situation, etc. may radically affect the market opportunities for RETs.

Deterministic extrapolation methods are suggested only if sufficient data are unavailable for the reasonable use of a stochastic time-series model..$^{25}$ Deterministic methods do not use or provide information on residuals or disturbance terms and, as such, fail to address the main source of error in forecasts.

Therefore, stochastic time-series models are generally recommended over deterministic methods for three reasons. First, stochastic time-series models possess a higher degree of accuracy (EPRI 1982). Second, stochastic time-series models directly probe the error structure. As such, it is possible to construct confidence intervals around forecast estimates. Deterministic methods provide only point estimates, without information on the variability of the potential variable value to the forecast estimate. Third, disturbance term diagnostics programs have been developed for stochastic time-series models to aid the analyst in the choice of a final model design. Most time-series software packages include a wide range of diagnostic procedures (e.g., EPRI's Forecast Master). This information may be important to an analyst who is required to exculpate a chosen model. With deterministic methods this information (and, with it the ability to objectively support model design) is lacking.

${ }^{25}$ If this is the case, efforts should be made to collect additional data such that the deterministic methods may be replaced with a stochastic model as soon as a usable data base of reasonable size is developed. 


\section{Section 7: Econometric Models}

Econometric analysis uses historical data to estimate a functional relationship between a dependent or endogenous variable (e.g., installation of a new technology) and independent or exogenous variable(s) that have an influence (e.g., cost).

There are two general approaches to the econometric estimation of market penetration, indirect and direct. The indirect approach consists of three steps. First, a technology is selected and an econometric model is specified to estimate the technology's sales. Second, another econometric model is specified to estimate the total sales of market facing the technology. Finally, the sales of the specific technology is divided by total market sales; the level and degree of market penetration of the technology are calculated. The direct approach estimates the technology's market share using the technology's market share as the dependent variable. ${ }^{26}$

Although the end results should be the same, the focus and implications of the two approaches are quite different. In the indirect approach, the analyst is attempting to estimate not only the growth of the new technology but the growth of the total industry as well. This approach allows technological and market restrictions or constraints to be placed on total sales or the sales of the new technology. In some instances, it may be important to limit sales within reasonable bounds.

The direct approach addresses only the market share of the new technology. The behavior of the total industrial market is left to be developed elsewhere. The indirect approach is directly concerned with the size of the total market; the direct approach requires the size of the total market to be determined exogenously.

There are numerous ways of econometrically addressing these two approaches. Basically, one can break down the various econometric approaches into two sets of two mutually exclusive categories. Set one consists of linear and nonlinear models. The second set is composed of single and simultaneous equation systems.

Space does not permit an exhaustive review of all of the econometric techniques that may be applicable to market penetration analysis. Therefore, it was necessary to restrict the number of econometric techniques discussed. Selection of the reviewed econometric methods was based on approaches that were commonly used or methods that, with little effort, could be included in the menu of econometric approaches used to estimate market penetration. The following econometric techniques will be discussed in this section:

- Ordinary least squares

- Dummy variable technique

- Generalized least squares

- Nonlinear regression

- Two-stage least squares

- Seemingly unrelated regressions.

${ }^{26}$ Please see the Blackman model in Section 5. 
Econometrics is a combination of economic theory and statistics. The analyst uses the economic theory to hypothecate a functional relationship between a dependent variable and a set of independent variables. ${ }^{37}$ Statistical methods are then used to estimate the quantitative parameters in the function (EPRI 1982). Ordinary least-squares can be found in most spreadskeet software. However, the more sophisticated econometric techniques will require advanced statistical software packages such as SAS.

The use of econometric methods is a well-defined practice and allows for the employment of a large store of diagnostic tools. Generally, econometric analysis is used to develop an equation that can be used in some predictive capacity. These estimated values are compared to actual values, and residuals are calculated. The existence of a disturbance term implies that econometrics is a stochastic process. Thus, uncertainty can be treated explicitly, and confidence intervals can be calculated around predicted values. The main drawback of econometric andysis is that the data requirements can be significant.

Market penetration forecasting using econometric analysis generally includes four steps: (1) identification, (2) specification, (3) estimation, and (4) prediction. The first step requires the identification vit the exogenous factors affecting the variable under examination. The second step requires the analyst to specify the relationship between the dependent and independent variable (e.g., a linear or nonlinear relationship). The third step requires the estimation of the paraneter coefficients of the independent variables, which enumerates the relationship between the endogenous and exogenuus variables. Finally, the parameter coefficients are used with forecasted independent variables to predict the future behavior of the dependent variable (EPRI 1982).

One of the primary concerns in econometric analysis is the acquisition of the most efficient, unbiased, and consistent coefficients for use in estimation and prediction. Of fundamental importance in the estimation of the most unbiased and consistent entimators is the characteristics of the residual or distribance terms. In general, the desired characteristics of the error terms are that they have a zero mean $(E[\epsilon]=0), 23$ a constant variance $\left(\sigma^{2}\right),{ }^{29}$ and are uncorrelated to each other ${ }^{30}$ (Kennedy 1983). A good deal can be learned about the various econometric methods by examining the error structure. When appropriate, the discussion of a particular econometric method will also include a discussion of a particular problem in the disnurbance terms--a problem that the econometric technique was designed to account for or correct.

\section{Ordinary Least Squares}

The simplest econometric technique is univariate ordina-y least squares. In this method, the dependent variable $\left(y_{v}\right)$ is linearly related to an independent variable $\left(x_{v}\right)$. For example, one can hypothecate that an individual's consumption is a function of his or her income. The univariate ordinary least squares functional form is expressed as

\footnotetext{
${ }^{n}$ A set could consist of only one independent variable.

${ }^{2 \pi}$ If $E[\epsilon] \neq 0$ then a systematic bias is said to exist.

${ }^{2}$ For example, there exists a homoskedastic residual structure.

${ }^{30}$ For example, autocorrelation does not exist.
} 


$$
y_{1}=\alpha+\beta_{1} x_{t}+\varepsilon_{t}
$$

where $y_{1}$ is the dependent variable, $x_{1}$ is the independent variable, $\alpha$ is a constant, and $\beta_{1}$ is the constant linear relationship between the dependent variable and the independent variable.

The unexplained residuals are the differences between what the specified relationship estimates the value of the dependent variable to be and what the dependent variable's actual value is. The parameter coefficients $\alpha$ and $\beta$ are obtained by selecting values that minimize the sum of the square of the residuals, hence, the name "least squares." The accuracy of the prediction will be based on how small the deviation between the actual and the estimated dependent variable can be. The typical reasons why error terms are said to exist are: (1) leaving out important variables from the equation, (2) the unpredictable behavior of people, (3) varying behavior among individuals, and (4) errors of measurement (Kelejian and Oates 1981).

The understanding of the ordinary least squares or linear regression technique is sometimes aided by a graphical illustration. Figure 7-1 illustrates a univariate linear regression.

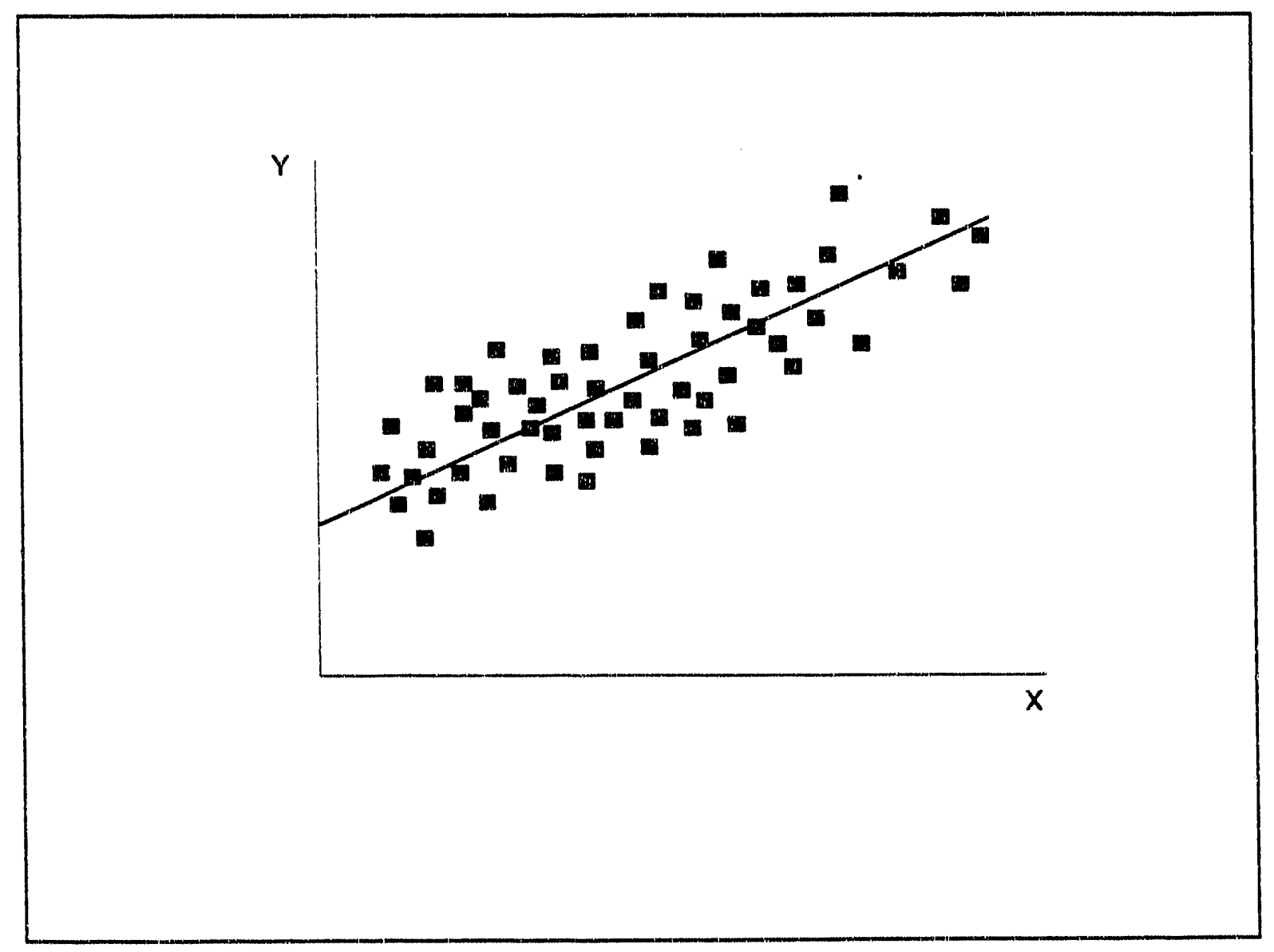

Figure 7-1. Ordinary least squares regression 
The relationship shown in Equation 7-1 implies that only one variable has an influence over $y_{t}$. In some situations that may be true. However, it is a more common situation that more than one factor affects the dependent variable.

If this is the case, then the previous relationship can be expanded to

$$
\mathrm{y}_{\mathrm{t}}=\alpha+\beta_{1} \mathrm{x}_{\mathrm{at}}+\beta_{2} \mathrm{x}_{2 \mathrm{t}}+\cdots+\beta_{\mathrm{n}} \mathrm{x}_{\mathrm{at}}+\varepsilon_{\mathrm{t}}
$$

where $y_{t}$ is the dependent variable, $x_{i t}$ 's are the independent variables, $\alpha$ is a constant, and $\beta_{i}$ 's are the parameter coefficient estimates of the relationships among the independent variables and the dependent variable. As with the univariate ordinary least squares regression, the multivariate ordinary least squares regression calculates the values that minimize the sum of the square of the error terms.

\section{Dummy Variable}

There are occasions when events occur that are hard to quantify but have important ramifications nonetheless. An example could be the 1978 Public Utilities Regulatory Policies Act or OPEC's actions in 1973. These two events may have structurally or fundamentally altered the economic environment ${ }^{31}$ of the time. If this is the case, then it is important for the analyst to incorporate this change into the modeling structure. One way to accomplish this is to use the dummy variable technique. Dummy variables are binary variables that are defined to have a value of 1 if a certain situation exists; otherwise their value is 0 . Once the dummies are introduced into the model's structure, they are treated like any other independent variable, and ordinary least squares can be run as before (Kmenta 1971). The inclusion of dummy variables is straightforward. This can be illustrated by modifying the previous equation to include a dummy variable as

$$
y_{t}=\alpha+\beta_{1} x_{1 t}+\beta_{2} x_{2 t}+\cdots+\beta_{\mathrm{z}} x_{x t}+\theta_{p} D_{p}+\varepsilon_{t}
$$

where $y_{t}$ is the dependent variable, $x_{i}$ 's are the independent variables, $\alpha$ is the intercept, and $\beta_{i}$ 's are the parameter coefficient estimates. $D_{p}$ is the dummy variable, which equals 1 if the year is greater than 1978 ( 0 otherwise); $\theta_{p}$ is an estimate of the difference between what $\alpha$ (i.e., the estimated intercept) is in the pre-1978 period and what the intercept will be in the post-1978 period (i.e., $\alpha+\theta_{\mathrm{p}}$ ).

Thus, through the use of the dummy variable technique, potential structural changes can be modeled. If the dummy's estimated coefficient $\left(\theta_{\mathrm{p}}\right.$ in the above example) is not statistically different from 0 , then it is implied that the specified equation did not exhibit the hypothecated structural change.

Care should be taken not to fall into the "dummy variable trap." The dummy variable trap occurs when all of the possible cases are specified with dummies. If an analyst forgets to omit a dummy variable for one category when an intercept term is included, then an exact linear relationship will exist between the intercept and the dummy variables (Kennedy 1983). If this is the case, the estimation procedure fails ${ }^{32}$ (Johnson 1972).

${ }^{31}$ Dummy variables are also particularly useful when dealing with qualitative data (Pindyck and Rubinfeld 1981).

${ }^{32}$ This results from the singularity of the regression matrix. 


\section{Generalized Least Squares}

One common problem that occurs is that the variance associated with the error term is not constant. ${ }^{33}$ Sometimes the error term's variance will bear a relationship with a dependent variable. Often increases in a dependent variable will correspond with increases in an error term's variance. Graphically, this would look like a cone, with the pointed end of the cone pointed toward the origin. Ordinary least squares is susceptible to this problem. Ordinary least squares estimation places more weight on observations that have large error variances than on those with small error variances. Consequently, the effect of the extreme values would be overemphasized in the estimation process. One way to correct this problem is to utilize an econometric technique called weighted or generalized least squares ${ }^{34}$ (Pindyck and Rubinfeld 1981).

In generalized least squares, the error terms are divided by the estimated standard deviation of the disturbance term (Kennedy 1983). This is accomplished by transforming the error terms by

$$
\sum_{i=1} \frac{\left(Y_{i}-\alpha-\beta X_{i}\right)}{\sigma_{i}}
$$

where $Y_{i}$ is the dependent variable, $\alpha$ is an estimated constant, $\beta$ is a vector of estimated parameter coefficients, $X_{i}$ is the independent variables, and $\sigma_{i}$ is the standard deviation for the $i$ error term.

After transforming the original data, the desired estimation procedure is to rerun ordinary least squares upon the transformed model (Pindyck and Rubinfeld 1981).

\section{Nonlinear Regressions}

It may be the case that the functional relationship between the dependent and the independent variables is not linear but is nonlinear. An example of a nonlinear relationship is presented in Figure 7-2.

There are a number of ways to address this problem; the simplest is to specify the relationship in double logarithmic form ${ }^{35}$ or to specify a squared term as a new variable. These two approaches are presented in the following two equations, respectively.

$$
\ln Y_{i}=\ln A+\alpha \ln K_{i}+\gamma \ln L_{i}+\varepsilon_{i}
$$

where $Y_{i}$ is the dependent variable, $A$ is a multiplicative constant, $K_{i}$ and $L_{i}$ are independent variables, $\alpha$ and $\gamma$ are parameter estimates, and $\epsilon_{\mathrm{i}}$ is the error term.

$$
Y_{i}=c+\alpha_{i} X_{i}+\gamma_{i} Z_{i}+\varepsilon_{i}
$$

where $Y_{i}$ is the dependent variable, $c$ is a constant, $x_{i}$ is an independent variable, $z_{i}$ is the independent variable squared $\left(\mathrm{X}^{2}\right), \alpha$ and $\gamma$ are parameter estimates, and $\epsilon_{i}$ is the error term.

\footnotetext{
${ }^{33}$ This is referred to as heteroskedasticity.

${ }^{34}$ Monte Carlo studies have also shown the maximum likelihood estimation technique to be effective in the correction of heteroskedasticity (Kennedy 1983).

${ }^{35}$ Where the estimated form is $\mathrm{Y}=\mathrm{AK} \mathrm{K}^{\alpha} \mathrm{L}^{\gamma}$.
} 


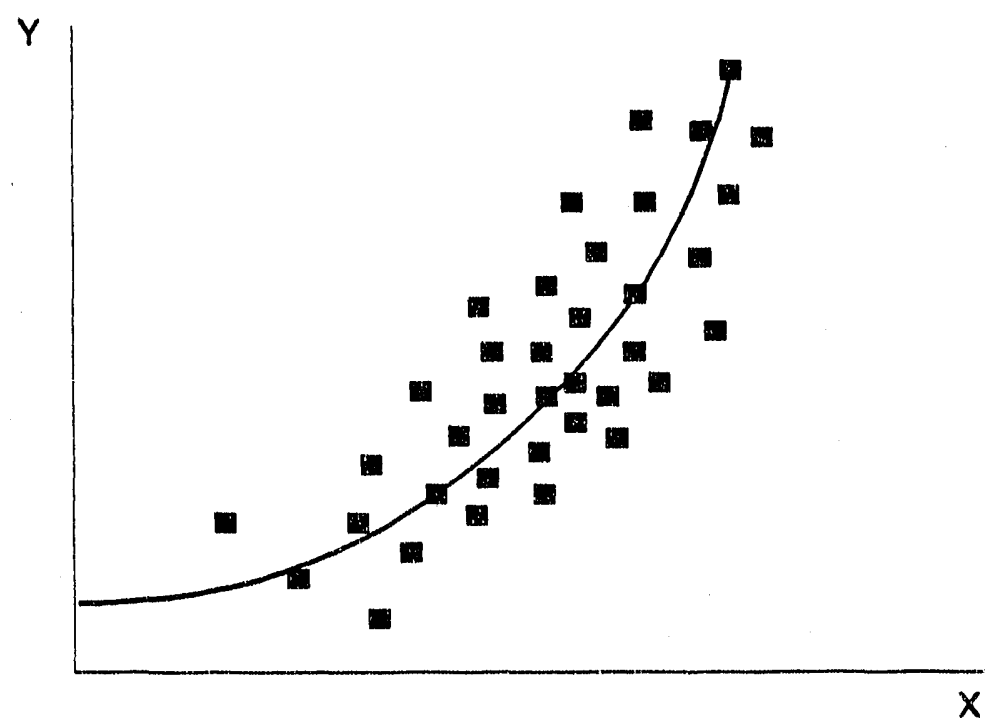

Figure 7-2. Nonlinear regression

An alternative nonlinear estimation approach is one used in the logit probability model. (The logit function is shown in Figure 7-3.) The logit model is based on the cumulative probability function

$$
\mathrm{P}_{i}=\mathrm{F}\left(\mathrm{Z}_{\mathrm{i}}\right)=\mathrm{F}\left(\alpha+\beta \mathrm{X}_{\mathrm{i}}\right)=\frac{1}{1+\mathrm{e}^{-\left(\mathrm{Z}_{\mathrm{i}}\right)}}=\frac{1}{1+\mathrm{e}^{-\left(\alpha+\beta \mathrm{X}_{i}\right)}}
$$

where $P_{i}$ is the probability that a corporation will make a certain choice given knowledge of $X_{i}$ (Pindyck and Rubinfeld 1981). Let expression $7-7$ represent a certain probability of choosing an alternative given an existing cost structure

$$
p_{i}=\frac{r_{i}}{n_{i}}
$$

where $p_{i}$ is the approximate probability of choice $P(i)$ for each identical group, $r_{i}$ equals the number of times the first alternative is chosen by corporations with costs of $i$, and $n_{i}$ is the number of corporations with costs of $i$. 
The logit probability model can be expressed in semi-logarithmic form as

$$
\log \frac{p_{i}}{1-p_{i}}=\log \frac{\left(\frac{r_{i}}{n_{i}}\right.}{\left(1-\left(\frac{r_{i}}{n_{i}}\right)\right.}=\log \frac{r_{i}}{\left(n_{i}-r_{i}\right)}=\alpha+\beta X_{i}+\varepsilon_{i}
$$

where $p_{i}$ is the approximate probability of choice $P(i), r_{i}$ equals the number of times the first alternative is chosen by corporations with costs of $i, n_{i}$ is the number of corporations with costs of $i, \alpha$ is a constant, $\beta$ is the parameter estimate on the effects of corporate costs, $X_{i}$ is the corporate costs of firm $i$, and $\epsilon_{i}$ is the error term (Pindyck and Rubinfeld 1981).

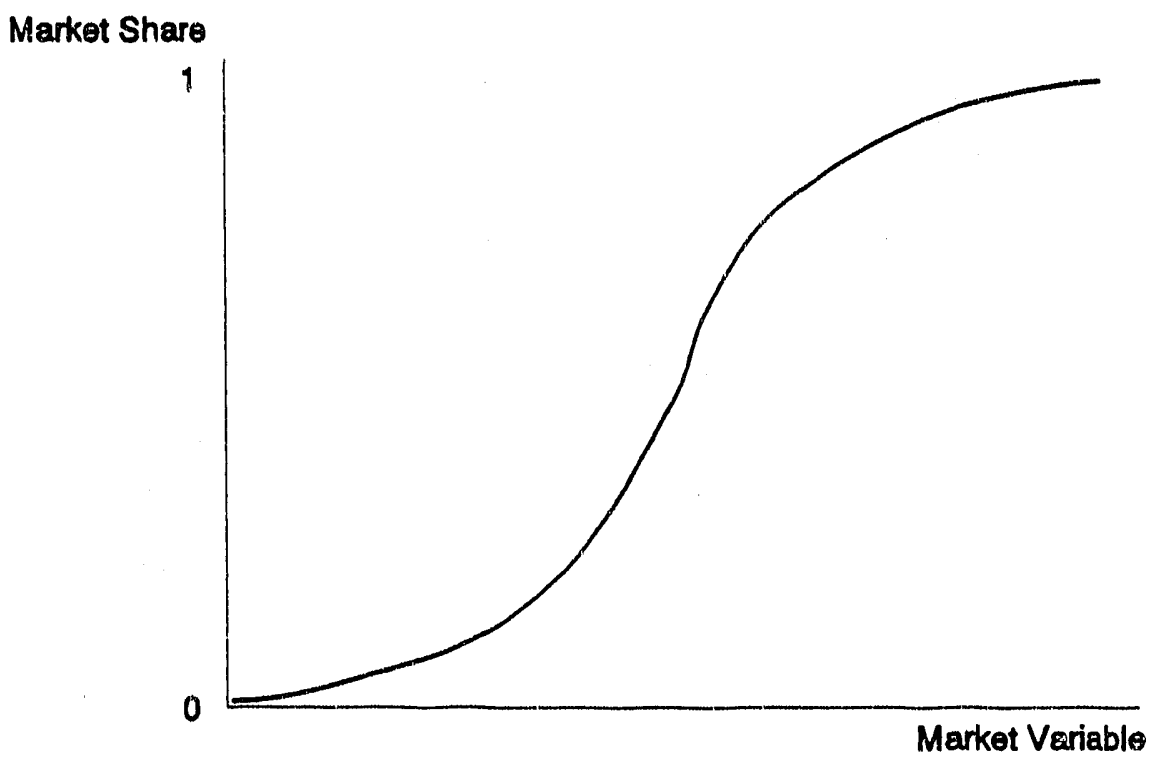

Figure 7-3. Logit function 


\section{Two-Stage Least Squares}

Thus far, only single equation systems have been discussed. In single equation systems, each equation is estimated individually. Single equation systems use only the information provided by that particular relationship or equation (Maddala 1977). Situations can occur in which the dependent variables are determined by the simultaneous interaction of several relationships. If this is the case, then a one-equation model is insufficient to estimate the actual relationships between the dependent and independent variables, and simultaneous equation estimation is indicated (Kennedy 1983). This commonly accurs when estimating market phenomena. Often it is insufficient to only estimate the demand for a product or technology. Market interactions between supply and demand are often missed if the analysis is only focused on demand or supply. A preferable approach would be to model both supply and demand in a simultaneous system, thereby using all of the market information available in the estimation procedure.

Over the years, econometricians have developed a number of techniques to address problems with simultaneous equation systems. The approach discussed here is two-stage least squares (2SLS). There were four reasons 2SLS was chosen to be presented here. First, 2SLS is easily understood and intuitively appealing. Second, if an equation system can be estimated, 2SLS will provide consistent estimates of the estimated parameter coefficients. Third, 2SLS makes relatively modest demands on computer time (Kelejian and Oates 1981). Finally, 2SLS is a recognized approach that is commonly included in statistical packages found in computer software.

The 2SLS procedure uses the information available from the specification of the equation system to obtain estimates for each structural parameter. In the first stage, the 2SLS procedure involves the creation of an instrument, while, in the second stage, 2SLS uses that instrument to calculate the structural parameters. Let there be a market system such that the structural model for the demand and supply of a new technology can be specified ${ }^{36}$ as

Supply: $\mathrm{Q}_{\mathrm{t}}=\alpha \mathrm{P}_{\mathrm{t}}+\varepsilon_{\mathrm{t}}$

$$
\text { Demand: } Q_{t}=\beta_{1} P_{t}+\beta_{2} \Pi+\beta_{3} w_{t}+\mu_{t}
$$

where $Q_{t}$ is the amount of a new technology in the market at time $t, \alpha$ and $\beta_{i}$ 's are estimated parameter coefficients, $P_{t}$ is the price for $Q$ at time $t, \Pi_{t}$ is the amount of corporate profit at time $t, w_{t}$ is another independent variable (e.g., dernand for the finished corporate product), and $\mu_{q}$ is the error term.

Before the 2SLS procedure can be initiated, it is necessary to specify the previous two equations in reduced form. Through mathematical manipulation, the reduced form develops a separate equation for

${ }^{36}$ The approach illustrated here was adopted from Pindyck and Rubinfeld (1981). 
the quantity of new technology in the marketplace and the price of the new technology. The reduced form equations are

$$
\begin{aligned}
& \mathrm{Q}_{\mathrm{t}}=\theta_{12} \mathrm{I}_{\mathrm{t}}+\theta_{13} \mathrm{~W}_{\mathrm{t}}+\mathrm{e}_{1 \mathrm{t}} \\
& \mathrm{P}_{\mathrm{t}}=\theta_{22} \Pi_{\mathrm{t}}+\theta_{23} \mathrm{w}_{\mathrm{t}}+\mathrm{e}_{2 \mathrm{t}}
\end{aligned}
$$

where $Q_{t}$ is the amount of a new technology in the market at time $t, P_{t}$ is the price for $Q$ at time $t, \Pi_{1}$ is the amount of corporate profit at time $t, w_{t}$ is another independent variable, $\theta_{i j}$ 's are estimated parameter coefficients, and $e_{\mathfrak{i}}$ 's are the error terms (Pindyck and Rubinfeld 1981).

The 2SLS technique is accomplished by executing the following two steps. First, the reduced form of $P_{t}$ is estimated using ordinary least squares. This is accomplished by regressing $P_{t}$ on the independent variables in the system. From this regression, estimated values of $P_{t}$ are obtained $\left(p_{t}\right)$. The estimated values $p_{l}$ are associated with an error structure $e_{i a}$, which is independent of the error terms $\epsilon_{t}$ and $\mu_{4}$. In the second step of 2SLS, the estimated values of price $p_{t}$ are substituted for $P_{q}$ in the supply equation and ordinary least squares is executed to estimate the supply equations parameter coefficients.

The 2SLS procedure can be described as a two-step transformation (or instrumental variable). In the first step', 2SLS eliminates that part of the independent variable that is correlated to the error term. This process generates a revised (uncorrelated) set of independent variable values. The second step uses these revised values and estimates the parameters using a standard ordinary least squares technique (Kelejian and Oates 1981). 2SLS is a legitimate instrumental variable estimator. As such, it is consistent (Kennedy 1983). Monte Carlo studies have shown that 2SLS estimated parameter coefficients are robust. More importantly for new technology analysis, 2SLS has superior small-sample properties (Summers 1965).

\section{Seemingly Unrelated Regression}

A set of demand equations for related prnducts can similarly be specified simultaneously. However, if the disturbances of the equations are uncorrelated, then there exists no relationship among the equations. In this situation, ordinary least squares estimation is appropriate, and regression coefficients are unbiased and efficient (Pindyck and Rubinfeld 1981). This is only the case if the model specification represents all of the information about the regression equations and the variables therein. If some information has been ignored or overlooked, then desired characteristics of the ordinary least squares estimators can no longer be assumed.

Of particular interest is the information concerning the relationship of the error structures across equations. That is, are the disturbance terms of one equation correlated with the error terms of another equation? If this is the case, then there is a possible efficiency gain by considering all of the equations at the same time (Judge et al. 1982). An econometric technique ${ }^{37}$ designed to accomplish this is called seemingly unrelated regressions (Zellner 1962). ${ }^{38}$

\footnotetext{
${ }^{37}$ To the best of the author's knowledge, the seemingly unrelated regression technique has not been applied to the study of RETs.

${ }^{38}$ The seemingly unrelated regression technique is also referred to as Zellner's seemingly unrelated regression technique, after the technique's developer.
} 
Seemingly unrelated regressions might apply to RETS. For example, consider the following model specifications for three RETs.

$$
\begin{aligned}
& \operatorname{RET}_{1 \mathrm{t}}=\beta_{11} \mathrm{X}_{1 \mathrm{t}, 1}+\beta_{12} \mathrm{X}_{1 \mathrm{t}, 2}+\cdots+\beta_{1 \mathrm{n}} \mathrm{X}_{1 \mathrm{t}, \mathrm{n}}+\varepsilon_{\mathrm{tt}}
\end{aligned}
$$

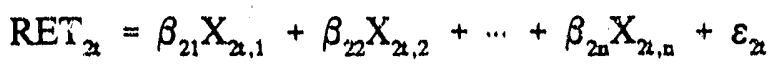

$$
\begin{aligned}
& \operatorname{RET}_{31 t}=\beta_{31} \mathrm{X}_{3 t, 1}+\beta_{32} \mathrm{X}_{3 \mathrm{t}, 2}+\cdots+\beta_{3 \mathrm{n}} \mathrm{X}_{3 \mathrm{t}, \mathrm{t}}+\varepsilon_{3 \mathrm{t}}
\end{aligned}
$$

where $\mathrm{RET}_{\text {it }}$ is the $\mathrm{i}^{\text {th }}$ renewable energy technology (e.g., wind, solar thermal, and photovoltaics), $\mathrm{X}_{i \mathrm{i}, \mathrm{j}}$ 's are commonly assumed independent variables (e.g., total life-cycle cost and energy price), $\beta_{\mathrm{ij}}$ 's are the estimated parameter coefficients, and $\epsilon_{\mathfrak{i}}$ 's are the error terms.

Let the previous model be specified using the standard economic factors as explanatory variables. In doing so, it is possible for two situations to exist. First, the set of explanatory variables will not be identical for each RET (e.g., different total life-cycle costs). Second, there may be nonzero correlations between the error terms in two or more equations (e.g., between the solar thermal and photovoltaics equations). If these conditions are met, then Zellner's seemingiy unrelated regressions will be more efficient and provide better parameter estimates than ordinary least squares (Johnson 1972).

The reason that Zellner's seemingly unrelated regression estimated parameters are superior is that Zellner's technique accounts for contemporaneous errors across equations. These contemporaneous errors are not explained by the explanatory variables but are systematically related to all the technologies represented in the equation system. Thus, factors, such as public utility commissioners' true attitudes toward RETS, would not generally be completely reflected in the economic or explanatory variables. But these attitudes would be reflected uniformly across RET technologies and consequently reflected in the contemporaneous error structures within the simultaneous equation system.

The seemingly unrelated regression technique identifies the contemporaneous correlation in the error terms and removes its systematic influence from the parameter coefficient estimates. Therefore, Zellner's approach improves the estimating abilities of the simultaneous equation system. The possibility exists, therefore, that by modeling RETs within a seemingly unrelated regression framework, analysis may capture previously difficult to measure or quantify exogenous factors affecting RETS.

The main attraction of Zellner's approach is that exact quantification of the external factors is unnecessary. If the external factors are systematic and exist, such that two or more equations modeling RETs are affected, then the influence (if it exists) can be addressed within the seemingly unrelated regression framework. Finally, Zellner's seemingly unrelated regression technique is an accepted and proven econometric procedure. ${ }^{39}$ Moreover, its abilities and properties are well known.

\section{Evaluation}

The main advantages of the econometric models are that the methodology is well established and documented and formal diagnostic tests exist. Econometric models use a number of explanatory

\footnotetext{
${ }^{39}$ For a complete mathematical derivation of Zellner's seemingly unrelated regression, parameter estimating matrices, and derivation of the variance and covariance matrices, please see Kmenta (1971) or Judge (1982).
} 
variables; therefore, econometric analysis possesses the ability to address market issues beyond the scope of other forms of analysis. Econometric models are stochastic. Therefore, uncertainty analysis and confidence interval construction is possible.

The main and, in some instances, crippling drawback to econometric analysis is that some forms of econometric analysis have significant and demanding data requirements. 


\section{Section 8: Summary and Conclusions}

This report examined a broad spectrum of market penetration analysis techniques. Discussed were various aspects of subjective estimation methods, market surveys, historical analogy models, cost models, diffusion methods, time-series techniques, and econometric procedures. In examining these techniques, it became evident that no one market penetration method is a panacea. The choice of market penetration method is, in part, controlled by the availalle data. The data available for RET market penetration analysis is not uniform. Consequently, analysts must be flexible in their choice of models and be aware of the market penetration methodologies available.

The market penetration technique selected should be the one that utilizes the available knowledge to the fullest. In some instances, this may necessitate combining a number of methods. For example, it may be necessary (because of lack of specific data) to use subjective estimates in cost methods incorporated in diffusion models. In general, stochastic models are preferred over deterministic models because they are more accurate, possess the ability to address uncertainty and confidence intervals, and allow for statistically valid diagnostic review and the objective determination of model design. However, when there exists a dearth of information, there exists a useful role for deterministic analysis, historical analozy methods, market surveys, and subjective judgments.

This report was designed to review market penetration models to help develop understanding of the market penetration studies for RETs. Seven broad categories, with more than 30 different models, methods, or techniques were covered. This was done to provide the reader with the necessary broad base to make informed decisions or judgments.

In a continuation of this effort, this report includes an extensive bibliography. This bibliography was carefully chosen to provide the reader with an up-to-date, well-rounded selection of material on market penetration. Moreover, articles and books on specific topic areas outside the purview of market penetration analysis, but tangentially related to it, are also included (e.g., small-sample properties of econometric techniques [Summers 1965]). 


\section{References}

Au, Tung and Thomas P. Au. 1983. Engineering Economics for Capital Investment Analysis. Boston: Allyn and Bacon.

Bass, Frank M. 1969. "A New Product Growth Model for Consumer Durables." Management Science. 15:215-227.

Blackman, A. Wade, Jr. 1974. "The Market Dynamics of Technological Substitutions." Technological Forecasting and Social Change, 6:41-63.

Box, G. E. P. and G. M. Jenkins. 1976. Times Series Analysis: Forecasting and Control. Rev. ed., San San Francisco: Holden-Day.

Brown, Robert J. and Rudolph R. Yanuck. 1980. Life-Cycle Costing: A Practical Guide for Energy Managers. Atlanta: Fairmont Press Inc.

Charles River Associates Inc. 1986. Capital Budgeting for Utilities: The Revenue Requirements Method. EPRI Research Project EA-4879, Palo Alto: Electric Power Research Institute. 1920-3-1.

Chow, G. C. 1965. "Review of the Growth of Television Ownership in the United Kingdom Since the War: A Lognormal Model by A. P. Bain." Econometrica. 33:657-659.

Chow, Gregory C. 1983. Econometrics. New York: McGraw-Hill.

Easingwood, Christopher, Vijay Mahajan, and Eitan Muller. 1981. "A Nonsymmetric Responding Logistic Model for Forecasting Technological Substitution." Technological Forecasting and Social Change. 20:199-213.

Easingwood, Christopher J., Vijay Mahajan, and Eitan Muller. 1983. "A Nonuniform Influence Innovation Diffusion Model of New Product Acceptance." Management Science. 2(3):273-295.

Electric Power Research Institute (EPRD). October 1982. Methods for Analyzing the Market Penetration of End-Use Technologies: A Guide for Utility Planners. EA-2702. Palo Alto, CA: Electric Power Research Institute.

Electric Power Research Institute (EPRD). 1987. TAG - Technical Assessment Guide, Volume 3: Fundamentals and Methods, Supply-1986. Palo Alto: Electric Power Research Institute.

Electric Power Research Institute (EPRD). 1991. Market Penetration of New Technologies, Programs and Services, EPRI CU-7011, Project 2864-1. Palo Alto: Electric Power Research Institute.

Fisher, J.C. and R.H. Pry, 1971. "A Simple Substitution Model of Technological Change." Technological Forecasting and Social Change. 3:75-88.

Floyd, A. 1962. "Trend Forecasting: A Methodology for Figure of Merit." In Technological Forecasting for Industry and Government: Methods and Applications, edite $\mathrm{J}$ by J. Bright. Englewood Cliffs: Prentice-Hall, Inc. 95-105. 
Fourt, Louis A. and Joseph W. Woodlock. 1960, "Early Prediction of Market Success for New Grocery Products." Journal of Marketing. 25:31-38.

Friedman, Milton. 1953. "The Methodology of Positive Economics." In Essays in Positive Econiomics, Chicago: University of Chicago Press.

Geurts, Michael D: and James E. Reinmuth. 1980. "New Product Sales Forecasting Without Past Sales Data." European Journal of Operational Research. 4:84-94.

Jeuland, Abel P. July 1981. "Parsimonious Models of Diffusion of Innovation: Part A, Derivations and Comparisons." Working Paper. Chicago, IL: Graduate School of Business, University of Chicago.

Johnson, J. 1972. Econometric Methods. New York: McGraw-Hill Book Company.

Judge, G., C. Hill, W. Griffiths, H. Lulkepohl, and T. C. Lee. 1982. Introduction to the Theory and Practice of Econometrics. New York: John Wiley and Sons, Inc.

Kalish, Shlomo. 1985. "A New Product Adoption Model With Pricing, Advertising, and Uncertainty." Management Science. 31:1569-1585.

Kalish, Shlomo and Gary L. Lilien. 1986. "A Market Entry Timing Model for New Technologies." Managernent Science. 32(2):194-205.

Kelejian, H. and W. Oates. 1981 Introduction to Econometrics: Principles and Applications. New York: Harper and Row Publishers.

Kennedy, Peter. 1983. A Guide to Econometrics. Cambridge: MrT Press.

Kmenta, Jan. 1971. Elements of Econometrics. New York: Macmillan Publishing Co., Inc.

Lawrence, Kenneth D. and William H. Lawton. 1981. "Applications of Diffusion Models: Some Empirical Results." In New-Product Forecasting, edited by Y. Wind, V. Mahajan, and R.N. Cardozo. Lexington, MA: D.C. Heath.

Lekvall, Per and Clas Wahlbin. 1973. "A Study of Some Assumptions Underlying Innovation Diffusion Functions." Swedish Journal of Economics. 75:362-377.

Maddala, G.S. 1977. Econometrics. New York: McGraw-Hill Company.

Mahajan, Vijay, Eitan Muller and Frank M. Bass. 1990. "New Product Diffusion Models in Marketing: A Review and Directions for Research." Journal of Marketing. 54(1).

Mahajan, Vijay and Robert A. Peterson. 1978. "Innovation Diffusion in a Dynamic Potential Adopter Population." Management Science. 24(15):1589-1597.

Mahajan, Vijay, Robert A. Peterson, Arun K. Jain, and Naresh Malhotra. 1979. "A New Product Growth Model with a Dynamic Market Potential." Long Range Planning. 12:51-58.

Mahajan, Vijay and Subhash Sharma. 1986. "A Simple Algebraic Estimation Procedure for Innovation Diffusion Models of New Product Acceptance." Technological Forecasting and Social Change. 30:331-345. 
Mansfield, Edwin. 1961. "Technical Change and the Rate of Imitation." Econometrica. 29(4):741-766.

Nelder, J. A. 1962. "An Alternative Form of a Generalized Logistic Equation." Biometrics. 18:614-16

Nelson, Charles R. 1973. Applied Time Series Analysis For Managerial Forecasting. San Francisco: Holden-Day.

Palm, Thomas and Abdul Qayum. 1985. Private and Public Investment Analysis. Cincinnati: SouthWestern Publishing Co.

Philipson, Lloyd L. 1978. "Market Penetration Models for Energy Production Devices and Conservation Techniques." Technological Forecasting and Social Change. 11:223-236.

Pindyck, Robert S. and Daniel L. Rubinfeld. 1981. Econometric Models and Economic Forecasts. Second edition, New York: McGraw-Hill.

Raju, P.S. and A.P.S. Teotia. (1985). An Evaluation of Market Penetration Forecasting Methodologies for New Residential and Commercial Energy Technologies. Technical Memo: ANL/EES-TM-315. Chicago: Argonne National Laboratory.

Rebibo, K., G. Bennington, P. Curto, P. Spewak, and R. Vitray. September 1977. A System for Projecting the Utilization of Renewable Resources: SPURR Methodology. MITRE Technical Report, MTR-7570. Prepared for U.S. Energy Research and Development Administration, Division of Solar Energy. Contract No. E-(4918)-2322, Project No. 15610. McLean, Virginia.

Ruegg, Rosalie. 1987. Life-Cycle Costing Manual for the Federal Management Programs. NBS Handbook 135, Washington D. C.: Government Printing Office.

Sharif, M. Nawaz and Chowdhury Kabir. 1976. "A Generalized Model for Forecasting Technological Substitution." Technological Forecasting and Social Change. 8:353-364.

Short, Walter. 1983. Guide to Economic Assessment of Conservation and Solar Technologies: Method and Data. Prepared for the U. S. Department of Energy, Contract No. EG-77-C-01-4042, Golden: Solar Energy Research Institute.

Simon, Herman and Karl-Heinz Sebastian. 1987. "Diffusion and Advertising: The German Telephone Company." Management Science. 33:451-466.

Srinivasan, V. and Charlotte H. Mason. 1986. "Nonlinear Least. Squares Estimation of New Product Diffusion Models." Marketing Science. 5(2):169-178.

Stover, John G. 1978. "Use of Decision Modeling for Substitution Analysis: Application to Acceptance of New Electricity-Generating Technologies." Technological Forecasting and Social Change. 12:337351.

Summers, R. 1965. "A Capital-Intensive Approach to the Small-Sample Properties of Various Simultaneous-Equation Estimators." Econometrica. 33:1-41.

Teotia, A.P.S. and P.S. Raju. 1986. "Forecasting the Market Penetration of New Technologies Using a Combination of Economic Cost and Diffusion Models." Journal of Product Innovation Management. 4:225-237. 
Tyebjee, Tyzoon T. 1987. "Behavioral Biases in New Product Forecasting." International Journal of Forecasting. 3:393-404.

Varian, Hal R. 1984. Microeconomic Analysis. Second Edition, New York: W. W. Norton and Company.

Von Bertalanffy, L. 1957. "Quantitative Laws in Metabolism and Growth." Quarterly Review of Biology. 32:217-231.

Wachs, Martin. 1982. "Ethical Dilemmas in Forecasting for Public Policy." Public Management Forum. 42:562-567.

Warren, E.H., Jr. 1980. "Solar Energy Market Penetration Models: Science of Number Mysticism?" Technological Forecasting and Social Change. 16:105-118.

Weijo, R.O. and D.R. Brown. 1988. Estimating the Market Penetration of Residential Cool Storage Technology Using Economic Cost Modeling. Presented at Fifth Annual Symposium on Improving Energy Efficiency in Hot and Humid Climates. Richland: Pacific Northwest Laboratory.

Weston, Fred J. and Eugene F. Brigham. 1981. Managerial Finance. Seventh Edition, Hinsdale: The Dryden Press.

Zellner, A. 1962. "An Efficient Method of Estimating Seemingly Unrelated Regressions and Tests for Aggregation Bias." Joumal of the American Statistical Association. 57:348-368. 


\section{Bibliography}

Armstrong, J. Scott and Michael C. Grohman. 1972. "A Comparative Study of Methods for LongRange Market Forecasting." Management Science. 19(2):211-221.

Armstrong, J. Scott, William B. Denniston, Jr. and Matt M. Gordon. 1975. "The Use of the Decomposition Principle in Making Judgments." Organizational Behavior and Human Performance. 14:257-263.

Ashton, Alison Hubbard, and Robert H. Ashton. 1985. "Aggregating Subjective Forecasts: Some Empirical Results." Management Science. 31(12):1499-1508.

Assmus, Gert. 1984. "New Product Forecasting." Journal of Forecasting. 3:121-138.

Bass, Frank M. 1980. "The Relationship Between Diffusion Rates, Experience Curves, and Demand Elasticities for Consumer Durable Technological Innovations." Journal of Business. 53(3.2):S51-S67.

Battelle Memorial Institute. 1985. Forecasting in an Era of Technological Change: Proceedings of the Fifth Forecasting Symposium. EPRI EA-4031, Project 2279-3, Palo Alto: Electric Power Research Institute.

Berkowitz, Marvin. 1986. "New Product Adoption by the Buying Organization: Who Are the Real Influencers?" Industrial Marketing Management. 15:33-43.

Berry, Linda. 1990. The Market Penetration of Energy-Efficiency Programs. Report prepared for Office of Energy Resources, Bonneville Power Administration. Report No. ORNL/Con-299, Oak Ridge, TN: Oak Ridge National Laboratory.

Bettman, James R. 1971. "The Structure of Consumer Choice Processes." Journal of Marketing Research. 8:465-471.

Blattberg, Robert and John Golanty. 1978. "Tracker: An Early Test Market Forecasting and Diagnostic Model for New Product Planning." Journal of Marketing Research. 15:192-202.

Bonoma, Thomas V. and Benson P. Shapiro. February 1983. Industrial Market Segmentation: A Nested Approach. Cambridge, MA: Marketing Science Institute. Report No. 83-100.

Bowersox, Donald J., Daviơ J. Closs, John T. Mentzer, Jr., and Jeffrey R. Sims. 1981. "Simulated Product Sales Forecasting: A Model for Short-Range Forecasting and Operational Decision Making." In Research in Marketing, Vol. 4, edited by Jagdish N. Sheth. Greenwich, CT: JAI Press Inc.

Bretschneider, Stuart and Barry Bozeman. 1986. "Adaptive Diffusion Models for the Growth of Robotics in New York State Industry." Technological Forecasting and Social Change. 30:111-121.

Bretschneider, Stuart I. and Vijay Mahajan. 1980. "Adaptive Technological Substitution Models." Technological Forecasting and Social Change. 18:129-139.

Bright, James R., ed. 1968. Technological Forecasting for Industry and Government: Methods and Applications. Englewood Cliffs, NJ: Prentice-Hall, Inc. 
Brown, Lawrence A., Marilyn A. Brown, and C. Samuel Craig. 1981. "Innovation Diffusion and Entrepreneurial Activity in a Spatial Context: Conceptual Models and Related Case Studies." In Research in Marketing, Vol. 4, edited by Jagdish N. Sheth. Greenwich, CT: JAI Press Inc.

Carbone, Robert and Wilpen L. Gorr. 1985. "Accuracy of Judgmental Forecasting of Time Series." Decision Sciences. 16:153-16.

Cardozo, Richard N. 1983. "Modeling Organizational Buying as a Sequence of Decisions." Industrial Marketing Management. 12:75-81.

Chakravarti, Kipankar, Andrew Mitchell, and Richard Staelin. 1979. "Judgment Based Marketing Decision Models: An Experimental Investigation of the Decision Calculus Approach." Management Science. 25(3):251-263.

Choffray, Jean-Marie and Gary L. Lilien. 1976. "Models of the Multiperson Choice Process with Application to the Adoption of Industrial Products." Working Paper No. 861-76. Cambridge, MA: Sloan School of Management, Massachusetts Institute of Technology.

Choffray, Jean-Marie and Gary L. Lilien. 1980. "A Model Based Methodology for Assessing Market Response for New Industrial Products." In Research in Marketing, Vol. 3, edited by Jagdish N. Sheth. Greenwich, CT: JAI Press Inc.

Chow, Gregory C. 1967. "Technological Change and the Demand for Computers." American Economic Review. 57:1118-1130.

Claycamp, Henry J. and Lucien E. Liddy. 1969. "Prediction of New Product Performance: An Analytical Approach." Journal of Marketing Research. 6:414-420.

Cox, William E., Jr. 1987. "Product Life Cycles as Marketing Models." Journal of Business. 40(4):375-384.

Cragg, J. G. 1967. "On the Relative Small-Sample Properties of Several Structural-Equation Estimators," Econometrica. 35:109

Cunningham, Scott M. 1966. "Perceived Risk as a Factor in the Diffusion of New Product Information." In Science Technology and Marketing, edited by Raymond M. Haas. Chicago, IL: American Marketing Association.

Curry, Joseph. 1989. "Understanding Conjoint Analysis in 15 Minutes." Quirk's Marketing Research Review.

Cyert, Richard M., W.R. Dill, and James G. March. 1958. "The Role of Expectations in Business Decision-Making." Administration Science Quarterly. 3:307-340.

Cyert, Richard M., James G. March, and William H. Starbuck. 1961. "Two Experiments on Bias and Conflict in Organizational Estimation." Management Science. 7:254-264.

Dalrymple, Douglas J. December 1975. "Sales Forecasting Methods and Accuracy." Business Horizons. 69-73. 
Dalrymple, Douglas J. 1987. "Sales Forecasting Practices: Results from a United States Survey." IJF 3:379-391.

Darley, John M. and James R. Beniger. 1981. "Diffusion of Energy-Conserving Innovations." Journal of Social Issues. 37(2):150-171.

Davis, J. 1987. "Techniques in Marketing Forecasting." Management Decision. 25:62-70.

DeKluyver, Cornelis A. 1982. "A Comparative Analysis of the Bass and Weibull New Product Growth Models for Consumer Durables." New Zealand Operational Research. 10(2):99-130.

Dockner, Engelbert and Steffen Jorgensen. 1988. "Optimal Advertising Policies for Diffusion Models of New Product Innovation in Monopolistic Situations." Management Science. 34(1):119-130.

Dodds, Wellesley. 1973. "An Application of the Bass Model in Long-Term New Product Forecasting." Journal of Marketing Research. 10:308-311.

Dubin, Jeffrey A. 1986. "A Nested Logit Model of Space and Water Heat System Choice." Management Science. 5(2):112-124.

Einhorn, Hillel J. 1974. "Expert Judgment: Some Necessary Conditions and an Example." Journal of Applied Psychology. 59(5):562-571.

Electric Power Research Institute (EPR). 1987. Market Segmentation Research, Volumes 1 and 2. Electric Utility Market Research Monograph Series, Monograph 3, EM-4963. Palo Alto, CA: Electric Power Research Institute. EM-4963.

Eliashberg, Jehoshua, Charles S. Tapiero, and Yoram Wind. 1985. "New Product Diffusion Models with Stochastic Parameters." Working Paper No. 83-018R. Philadelphia, PA: Wharton School of the University of Pennsylvania.

Eliashberg, Jehoshua, et al. 1987. "Innovation Diffusion Models with Stochastic Parameters, Forecasting and Planning Implications." Working Paper No. 87-003. Pennsylvania, PA: Wharton School of the University of Pennsyivania.

Eskin, Gerald J. 1973. "Dynamic Forecasts of New Product Demand Using a Depth of Repeat Model." Journal of Marketing Research. 10:115-129.

Feichtinger, Gustav. 1982. "Optimal Pricing in a Diffusion Model with Concave Price-Dependent Market Potential." Operations Research Letters. 1(6):236-240.

Fliegel, Frederick C. and Joseph E. Kivlin. 1966. "Attributes of Innovations as Factors in Diffusion." The American Journal of Sociology. 72(3):235-248.

Forsund, Finn R. and Lennart Hjalmarsson. 1988. "Choice of Technology and Long-Run Technical Change in Energy-Intensive Industries." Energy Joumal. 9(3):79-97.

Gatignon, Hubert and Thomas S. Robertson. 1988. "The Adoption of New Technologies in a Competitive Environment.." Working Paper No. 88-007. Philadelphia, PA: Wharton School of the University of Pennsylvania. 
Gatignon, Hubert and Thomas S. Robertson. 1989. "Technology Diffusion: An Empirical Test of Competitive Effects." Journal of Marketing. 53:35-49.

Gensch, Dennis H. and Wilfred W. Recker. 1979. "The Multinomial, Multiattribute Logit Choice Model." Journal of Marketing Research. 16:124-132.

Gerstenfeld, Arthur. 1971. "Technological Forecasting." Journal of Business. 44(1):10-18.

Gore, A.P. and U.A. Lavaraj. 1987. "Innovation Diffusion in a Heterogeneous Population." Technological Forecasting and Social Change. 32:163-168.

Green, Paul E., Abba M. Kreiger, and Pradeep Bansal. 1988. "Completely Unacceptable Levels in Conjoint Analysis: A Cautionary Note." Journal of Marketing Research. 25:293-300.

Griliches, Zvi. 1957. "Hybrid Corn: An Exploration in the Economics of Technological Change." Econometrica. 25(4):501-522.

Gupta, Sunil and Peter C. Wilson. 1987. "Combination of Forecasts: An Extension." Management Science. 33(3):356-372.

Hagerstrand, Torsten. 1965. "A Monte Carlo Approach to Diffusion." European Journal of Sociology. $6: 43-67$.

Hanssens, Dominique M., et al. 1990. Market Response Models: Economerric and Time Series Analysis. Norwell, MA: Kluwer Academic Publishers.

Hausman, Jerry A. and David A. Wise. 1978. "A Conditional Probit Model for Qualitative Choice: Discrete Decisions Recognizing Interdependence and Heterogeneous Preferences." Econometrica. $46(2): 403-426$.

Herbert, Johr H. 1979. "Research Note: Some Comments on Market Penetration, Innovation, and Learning. The Case for Solar Technology." Technological Forecasting and Social Change. 14:259-261.

Hill, Kim Quaile and Jib Fowles. 1975. "The Methodological Worth of the Delphi Forecasting Technique." Technological Forecasting and Social Change. 7:179-192.

Hillier, Terry J. 1975. "Decision-Making in the Corporate Industrial Buying Process." Industrial Marketing Management. 4:99-106.

Holliday, Darryl R. and Howard E. Lowitt. 1984. "An Integer-Based Blackman Innovation Index: Hypothesis, Evidence, and Implications." Technological Forecasting arid Social Change. 26:59-79.

Hogarth, Robin M. and Spyros Makridakis. 1981. "Forecasting and Planning: An Evaluation." Management Science. 27:115-138.

Huber, Joel. 1975. "Bootstrapping of Data and Decisions." Journal of Consumer Research. 2:229-234.

Hurter, Arthur P., Jr. and Albert H. Rubenstein. 1978. "Market Penetration by New Innovations: The Technological Literature." Technological Forecasting and Social Change. 11:197-221. 
Hyman, Michael R. 1988. "The Timeliness Problem in the Application of Bass-Type New ProductGrowth Models to Durable Sales Forecasting." Journal of Business Research. 16(1):31-47.

Infosino, William J. 1986. "Forecasting New Product Sales from Likelihood of Purchase Ratings." Marketing Science. 5(4):372-384.

Jensen, Richard. 1982. "Adoption and Diffusion of an Innovation of Uncertain Profitability." Journal of Economic Theory. 27:182-193.

Jeuland, A.bel P. July 1987. "Incorporating Heterogeneity into Parsimonious Models of Diffusion of Innovation." Working Paper. Chicago, IL: Graduate School of Business, University of Chicago.

Jones, J. Morgan and Jane T. Landwehr. 1988. "Removing Heterogeneity Bias from Logit Model Estimation." Marketing Science. 7(1):41-59.

Jorgensen, Steffen. 1983. "Optimal Control of a Diffusion Model of New Product Acceptance with Price-Dependent Total Market Potential." Optimal Control Applications and Methods. 4:269-276.

Kamakura, Wagner A. and Siva K. Balasubramanian. 1987. "Long-term Forecasting with Innovation Diffusion Models: The Impact of Replacement Purchases." Joumal of Forecasting. 6:1-19.

Kamakura, Wagner A. and Gary J. Russell. 1989. "A Probabilistic Choice Model for Market Segmentation and Elasticity Structure." Joumal of Marketing Research. 26:379-390.

Katzman, Martin T. 1981. "Paradoxes in the Diffusion of a Rapidly Advancing Technology: The Case of Solar Photovoltaics." Technological Forecasting and Social Change. 19:227-236.

Keerney, Ralph L. and Gary L. Lilien. 1987. "New Industrial Product Design and Evaluation Using Multiattribute Value Analysis." Journal of Product Innovation Management. 4:185-198.

Kivlin, Joseph E. and Frederick C. Fliegel, 1967. "Differential Perceptions of Innovations and Rate of Adoption." Rural Sociology. 32(1):78-90.

Klinger, Walter H. 1977. "Measuring Market Potential for Industrial Products: An Eight-Step Approach." Industrial Marketing Management. 6:39-42.

Kotler, Philip. 1971. Marketing Decision Making: A Model Building Approach. New York: Holt, Rinehart and Winston, Inc.

Lackman, Conway L. 1977. "Gompertz Curve Forecasting: A New Product Application." Joumal of Marketing Research Society. 20(1):45-47.

Lakhani, Hyder. 1979. "Empirical Implications of Mathematical Functions Used to Analyze Market Penetration of New Products-Cigarettes Case Study." Technological Forecasting and Social Change. 15:147-156.

Lal, V.B., Karmeshu and S. Kaicker. 1988. "Modeling Innovation Diffusion with Distributed Time Lag." Technological Forecasting and Social Change. 34:103-113.

Larwood, Laurie and William Whittaker. 1977. "Managerial Myopia: Self-serving Biases in Organizational Planning." Journal of Applied Psychology. 62:194-198. 
Lessne, Greg J. and Choudary Hanumara. 1988. "Growth Curve Analysis in Marketing: Miethod and Application." Journal of Marketing Research. 25:391-396.

Lilien, Gary L. 1980. "The Implications of Diffusion Models for Accelerating the Diffusion of Innovation." Technological Forecasting and Social Change. 17:339-351.

Limaye, Dilip R. and Craig McDonald. 1987. "Assessing Market Penetration of New End-Use Technologies." In Demand-Side Management Strategies in Transition. Proceedings, Third National Conference on Utility DSM Programs, Houston, TX, June 16-18, 1987.

Lotus Development Company. 1991. Lotus 1-2-3 Release 3.1: Reference. Cambridge: Lotus Development Company.

Mahajan, Vijay and Eitan Muller. 1979. "Innovation Diffusion and New Product Growth Models in Marketing." Journal of Marketing. 43:55-68.

Mahajan, Vijay and Yoram Wind. 1988. "New Product Forecasting Models: Directions for Research and Implementation." International Journal of Forecasting. 4(3):341-358.

Mansfield, Edwin. 1963. "The Speed of Response of Firms to New Techniques." Quarterly Journal of Economics. $77: 290-311$.

Matlin, Margaret and David Stang. 1978. The Pollyanna Principle: Selectivity in Language, Memory and Thought. Cambridge: Schenkman.

McCardle, Kevin F. 1985. "Information Acquisition and the Adoption of New Technology." Management Science. 31(11):1372-1388.

McFadden, Daniel. 1980. "Econometric Models for Probabilistic Choice Among Products." Journal of Business. 53(3.2):S13-S29.

McFadden, Daniel. 1986. "The Choice Theory Approach to Market Research." Marketing Science. 5(4):275-297.

Moore, William L. and Donald R. Lehmann. 1989. "A Paired Comparison Nested Logit Model of Individual Preference Structures." Journal of Marketing Research. 26:420-428.

Morelock, H. 1967. "The Effect of Outcome Desirability on Information Required for Decisions." Behavioral Sciences. 12:296-300.

Naill, Roger F. 1976. C.O.A.L.: A Dynamic Model for the Analysis of United States Energy Policy. Ph.D. Dissertation, Dartmouth College.

Norland, Douglas L. 1987. "Explicit Use of Market Penetration in DSM Planning." In Demand-Side Management Strategies in Transition. Proceedings, Third National Conference on Utility DSM Programs. June 16-18. Houston, Texas.

O'Neal, Charles R., Hans B. Thorelli, and James M. Utterback. 1973. "Adoption of Innovation by Industrial Organizations." Industrial Marketing Management. 2:235-250. 
Olson, Jerome A. 1982. "Generalized Least Squares and Maximum Likelihood Estimation of the Logistic Function for Technology Diffusion." Technological Forecasting and Social Change. 21:241249.

Oren, Schmuel S. and Michael H. Rothkopf. 1984. "A Market Dynamics Model for New Industrial Products and Its Application." Marketing Science. 3(3):247-265.

Oren, Schmuel S. and Rick G. Schwartz, 1988. "Diffusion of New Products in Risk-Sensitive Markets." Journal of Forecasting. 7:273-287.

Ostlund, Lyman E. 1974. "Perceived Innovation Attributes as Predictors of Innovativeness." Journal of Consumer Research. 1:23-29.

Ozanne, Urban B. and Gilbert A. Churchill, Jr. 1971. "Five Dimensions of the Industrial Adoption Process." Journal of Marketing Research. 8:322-328.

Parente, Frederick J., Janet K. Anderson, Patrick Myers, and Thomas O'Brien. 1984. "An Examination of Factors Contributing to Delphi Accuracy." Joumal of Forecasting. 3:173-182.

Pessemier, Edgar A. December 1975. Managing Innovation and New Product Development. Cambridge, MA: Marketing Science Institute, Report No. 75-122.

Peterka, V. December 1979. "Macrodynamics of Technological Change: Market Penetration by New Technologies." Luxembourg: International Institute for Applied Systems Analysis, RR-77-22.

Polydyne, Inc. 1987. FA\$T 123: Financial Analysis Standard, Corporate and Intermediary Financing. San Mateo: Polydyne.

Raju, P.S. and A.P.S. Teotia. (1985). An Evaluation of Market Penetration Forecasting Methodologies for New Residential and Commercial Energy Technologies. Technical Memo: ANL/EES-TM-315. Chicago: Argonne National Laboratory.

Rao, Vithala R. and Frederick W. Wintter. 1978. "An Application of the Multivariate Probit Model to Market Segmentation and Product Design." Journal of Marketing Research. 15:361-368.

Robertson, Thomas S. and Hubert Gatignon. 1986. "Competitive Effects on Technology Diffusion." Journal of Marketing. 50:1-12.

Rogers, Everett M. 1976. "New Product Adoption and Diffusion." Journal of Consumer Research. 2:290-301.

Rose, Nancy L. and Paul I. Joskow. 1988. "The Diffusion of New Technologies: Evidence from the Electric Utility Industry." Working Paper No. 2676. Cambridge, MA: National Bureau of Economic Research.

Rosegger, Gerhard. 1976. "Diffusion Research in the Industrial Setting: Some Conceptual Clarifications." Technological Forecasting and Social Change. 9:401-410.

Rubinstien, Albert H., and Hans-Horst Schroder. 1977. "Managerial Differences in Assessing Probabilities of Technical Success for R\&D Projects." Management Science. 24:137-148. 
Sanatani, Sunoy, 1981. "Market Penetration of New Products in Segmented Populations: A System Dynamics Simulation with Fuzzy Sets." Technological Forecasting and Social Change. 19:313-329.

Schmittlein, David C. and Vijay Mahajan. 1982. "Maximum Likelihood Estimation for an Innovation Diffusion Model of New Product Acceptance." Marketing Science. 1(1):57-78.

Schultz, Randall L. and Andris A. Zoltners, eds. 1981. Marketing Decision Models. New York: Elsevier Science Publishing Company, Inc.

Sharif, I.. Nawaz and M. Nazrul Islam. 1980. "The Weibull Distribution as a General Model for Forecasting Technological Change." Technological Forecasting and Social Change. 18:247-256.

Sharif, M.N. and K. Ramanathan. 1981. "Binomial Innovation Diffusion Models with Dynamic Potential Adopter Population." Technological Forecasting and Social Change. 20:63-87.

Sharif, M.N. and K. Ramanathan. 1982. "Polynomial Innovation Diffusion Models." Technological Forecasting and Social Change. 21:301-323.

Shaw, Jim, Joe Giglierano and Jeff Kallis. 1989. "Marketing Complex Technical Products: The Importance of Intangible Attributes." Industrial Marketing Management. 18:45-53.

Silverman, Barry G. 1981. "Market Penetration Model: Multimarket, Multitechnology, Multiattribute Technological Forecasting." Technological Forecasting and Social Change. 20:215-233.

Skiadas, Christos. 1985. "Two Generalized Rational Models for Forecasting Innovation Diffusion." Technological Forecasting and Social Change. 27:39-61.

Slovic, P. 1966. "Value as a Determiner of Subjective Probability." In IEEE Transactions in Human Factors in Electronics. Institute of Electrical and Electronics Engineers. HFE-7:22-33.

Solar Energy Research Institute. 1990. The Potential of Renewable Energy: An Interlaboratory White Paper. Golden: SERI.

Solar Energy Research Institute. 1990. Renewable Energy Technology Evolution Rationales. Golden: SERI.

Statmen, Mier and Tyzoom T. Tyebjee. 1985. "Optimistic Capital Budgeting Forecasts: An Experiment." Financial Management. 14:27-33.

Taylor, Ronald N. 1982. "Organizational and Behavioral Aspects of Forecasting." In The Handbook of Forecasting, Spyros Makridakis and Stephen C. Wheelwright eds. New York: John Wiley.

Thomas, Robert J. 1985. "Estimating Market Growth for New Products: An Analogical Diffusion Model Approach." Journal of Product Innovation Management. 2:45-55. 
Tolley, G.S., R.J. Krumm, and E.K. Mensah. July 1982. Market Penetration Models and the Evaluation of Gas Technology, Appendix A: Working Papers on Household Adoption of Energy-Using Appliances and Fuel. Department of Economics and the Committee on Public Policy Studies, the University of Chicago. Prepared for the Gas Research Institute. Contract No. 5014-310-0294. Chicago, IL.

Tolley, G.S., R.J. Krumm, and E.K. Mensah. July 1982. Market Penetration Models and the Evaluation of Gas Technology, Appendix B: Working Papers on the Framework for Explaining Market Adoption Patterns. Department of Economics and the Committee on Public Policy Studies, the University of Chicago. Prepared for the Gas Research Institute. Contract No. 5014-310-0294. Chicago, IL.

Twiss, Brian C. 1984. "Forecasting Market Size and Market Growth Rates for New Products." Journal of Product Innovation Management. 1:19-29.

U.S. Department of Energy. 1986. National Solar Thermal Technology Program: Five Year Research and Development Plan 1986-1990. Springfield: National Technical Information Service.

Vescuso, Peter. 1982. The Dynamics of Photovoltaic Market Penetration: 1975-2020. M.S. Thesis, Dartmouth College.

Wind, Yoram, Thomas S. Robertson, and Cynthia Fraser, 1982. "Industrial Product Diffusion by Market Segment." Industrial Marketing Management. 11:1-8.

Wood, Lisa L. and Josephine A. Mauskopf. 1991 (forthcoming). "Forecasting Market Potential and Market Penetration of Residential Water Heater Load Control Programs." Journal of Forecasting. 10. 

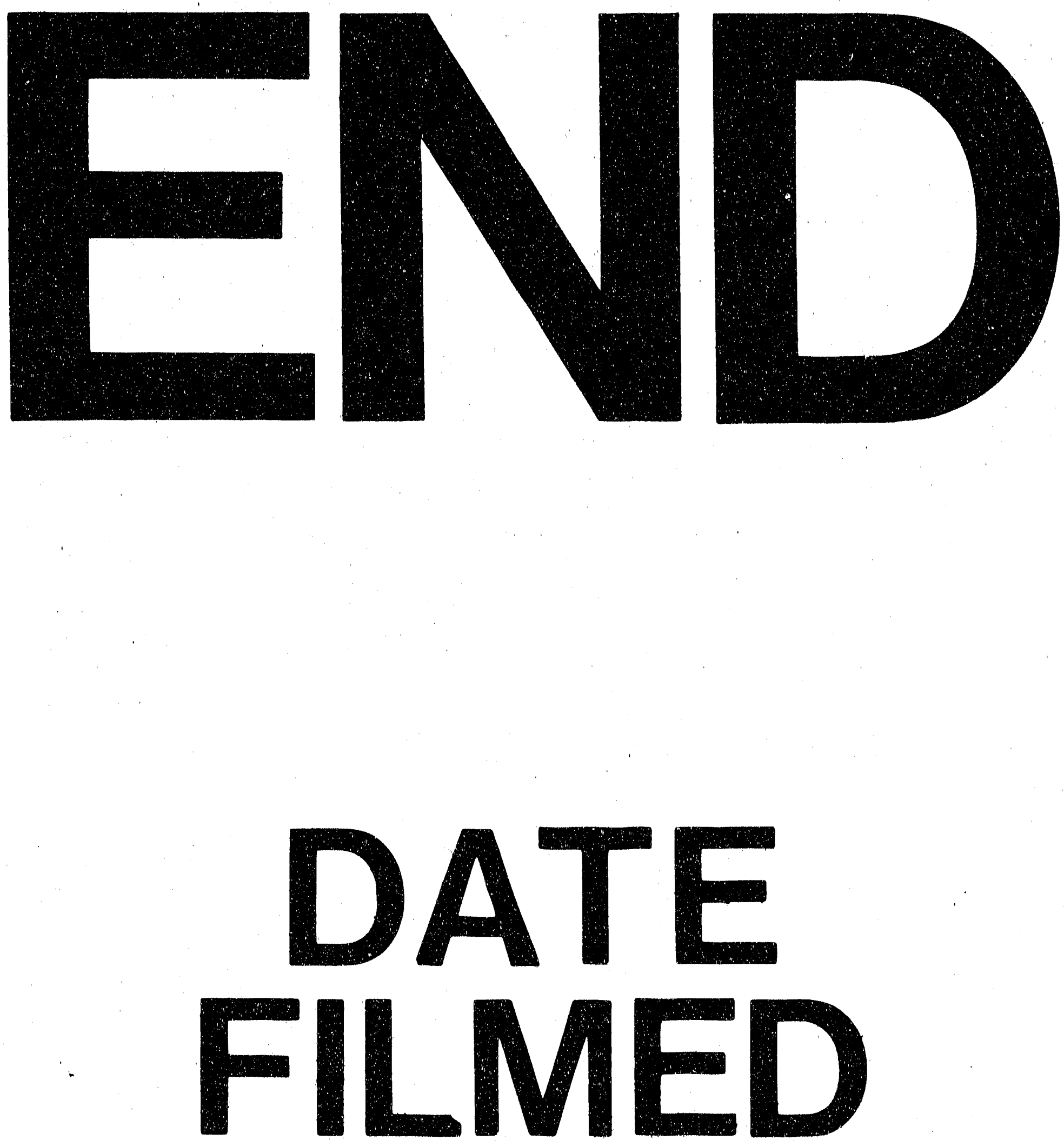

1
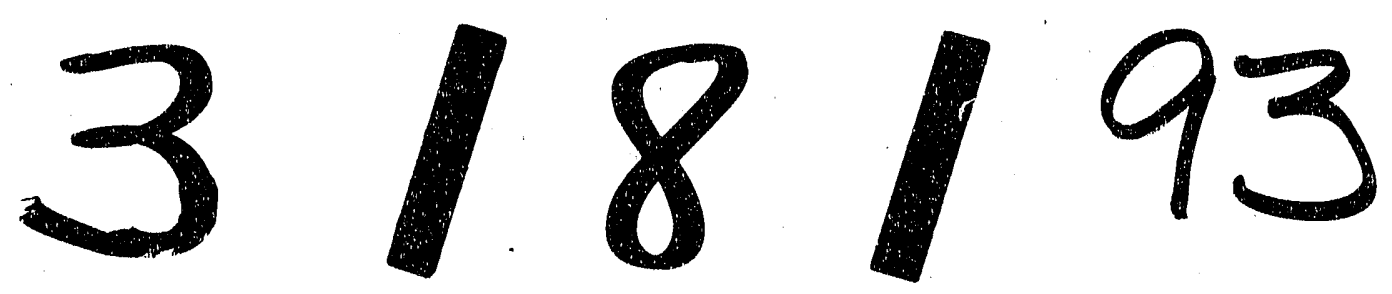
